\title{
Phosphorylcholine Phosphatase: A Peculiar Enzyme of Pseudomonas aeruginosa
}

\author{
Carlos Eduardo Domenech, Lisandro Horacio Otero, Paola Rita Beassoni, \\ and Angela Teresita Lisa
}

Departamento de Biología Molecular, Área Bioquímica, Facultad de Ciencias Exactas, Fisicoquímicas y Naturales, Universidad Nacional de Río Cuarto, Ruta Nacional 36 Km 601, 5800 Río Cuarto, Córdoba, Argentina

Correspondence should be addressed to Carlos Eduardo Domenech, cedomenech@gmail.com

Received 26 February 2011; Revised 31 May 2011; Accepted 7 June 2011

Academic Editor: Heung Chin Cheng

Copyright ( $) 2011$ Carlos Eduardo Domenech et al. This is an open access article distributed under the Creative Commons Attribution License, which permits unrestricted use, distribution, and reproduction in any medium, provided the original work is properly cited.

\begin{abstract}
Pseudomonas aeruginosa synthesizes phosphorylcholine phosphatase (PchP) when grown on choline, betaine, dimethylglycine or carnitine. In the presence of $\mathrm{Mg}^{2+}$ or $\mathrm{Zn}^{2+}, \mathrm{PchP}$ catalyzes the hydrolysis of $p$-nitrophenylphosphate ( $p$-NPP) or phosphorylcholine (Pcho). The regulation of $p c h P$ gene expression is under the control of GbdR and NtrC; dimethylglycine is likely the metabolite directly involved in the induction of PchP. Therefore, the regulation of choline metabolism and consequently PchP synthesis may reflect an adaptive response of $P$. aeruginosa to environmental conditions. Bioinformatic and biochemistry studies shown that PchP contains two sites for alkylammonium compounds (AACs): one in the catalytic site near the metal ion-phosphoester pocket, and another in an inhibitory site responsible for the binding of the alkylammonium moiety. Both sites could be close to each other and interact through the residues ${ }^{42} \mathrm{E},{ }^{43} \mathrm{E}$ and ${ }^{82} \mathrm{YYY}^{84} . \mathrm{Zn}^{2+}$ is better activator than $\mathrm{Mg}^{2+}$ at $\mathrm{pH} 5.0$ and it is more effective at alleviating the inhibition produced by the entry of Pcho or different AACs in the inhibitory site. We postulate that $\mathrm{Zn}^{2+}$ induces at pH 5.0 a conformational change in the active center that is communicated to the inhibitory site, producing a compact or closed structure. However, at $\mathrm{pH} 7.4$, this effect is not observed because to the hydrolysis of the $\left[\mathrm{Zn}^{2+} \mathrm{L}_{2}^{-1} \mathrm{~L}_{2}^{0}\left(\mathrm{H}_{2} \mathrm{O}\right)_{2}\right]$ complex, which causes a change from octahedral to tetrahedral in the metal coordination geometry. This enzyme is also present in $P$. fluorescens, $P$. putida, P. syringae, and other organisms. We have recently crystallized PchP and solved its structure.
\end{abstract}

\section{Introduction}

Bacteria possess multiple proteins with the capacity to catalyze the hydrolysis of phosphoric esters in either acidic or alkaline media. In addition to having different optimal $\mathrm{pH}$ values for their activity, these enzymes differ in their dependence on metal ions, which are generally divalent cations found in the second or third period of the periodic table. In our previous review, we summarized work showing that the synthesis of Pseudomonas aeruginosa phosphorylcholine phosphatase (PchP) in the presence of low or high orthophosphate concentration depends on choline, betaine, dimethylglycine, or carnitine added to the culture medium as the carbon and/or nitrogen source. In addition, the gene for PchP was located, and the most current information on the kinetic, biochemical, biophysical, and molecular characteristics of PchP was summarized [1]. Phosphorylcho- line (Pcho), phospho-rylethanolamine, and $p$-nitrophenylphosphate ( $p$-NPP), substrates of PchP, are hydrolyzed to orthophosphate plus choline, ethanolamine, and $p$-nitrophenol, respectively $[2,3]$. Because $P$. aeruginosa is an opportunistic Gram-negative bacterium capable of producing infections at different levels in higher organisms, we dedicated our effort toward in-depth characterization of PchP. Therefore, this paper focuses on fundamental studies at the molecular, biochemical, bioinformatic, and biophysical levels, with the goal of compiling all current information on PchP.

\section{Molecular Studies}

PA5292 was identified as the locus encoding PchP in the $P$. aeruginosa $\mathrm{PAO} 1$ genome using various microbiological 
and molecular experiments [4]. After this identification our interest was focused on the regulation of $p c h P$ gene expression. Wargo et al. reported that the induction of pchP transcription by glycine betaine, a product of choline oxidation, via betaine aldehyde, is mediated by GbdR, an AraC family transcription factor [5]. The same authors also described GbdR as a specific regulator of genes involved in choline metabolism [6]. The construction of a $\Delta g b d \mathrm{R}$ strain allowed us to confirm the direct impact of GbdR on choline catabolic genes because no growth was detected with this mutant in media with choline, choline $/ \mathrm{NH}_{4}{ }^{+}$, or choline/succinate [7]. In addition, with wild-type $P$. aeruginosa, we have also observed that choline, betaine, dimethylglycine, or carnitine (which is metabolized to betaine) utilization was absolutely necessary for the synthesis of PchP [8-10]. In addition, it is known that in the absence of preferred sources, a two-component system comprising the global regulators $\mathrm{NtrBC}$ and $\mathrm{CbrAB}$ is activated by the depletion of nitrogen and carbon in many bacteria including $P$. aeruginosa [11-13]. As choline and the various amino acids are not typically preferred carbon or nitrogen sources, we hypothesized that besides GbdR, enzymes whose synthesis is dependent on choline catabolism might be also under the control of NtrBC and/or CbrAB. In control experiments with histidine where $\mathrm{NtrBC}$ and $\mathrm{CbrAB}$ were activated $[11,12]$, no $\beta$-galactosidase activity (a measure of pchP expression) was detected [7]. The specific induction produced by choline led us to focus other experiments in this direction, utilizing $\Delta c b r \mathrm{~B}, \Delta n t r \mathrm{C}$, and $\Delta n t r \mathrm{C} / \Delta c b r \mathrm{~B}$ mutants of $P$. aeruginosa $\mathrm{PAO} 1$, containing the construction P1::lacZ (7) inserted into the bacterial chromosome. These experiments showed that $\mathrm{CbrB}$ is crucial when choline is the only nutrient for growth because it was observed that the $\Delta c b r \mathrm{~B}$ strain did not grow in media containing choline as a carbon or carbon/nitrogen source [7]. With choline as nitrogen source and succinate as carbon source, growth of the $\Delta c b r \mathrm{~B}$ mutant was evident, and the increase of $\beta$ galactosidase activity was similar to the observed in the wildtype strain [7]. Contrary to experiments with the $\Delta c b r \mathrm{~B}$ mutant, the $\Delta n t r C$ strain did not grow in a choline/succinate medium but did grow in media containing choline as the carbon or carbon/nitrogen source. In these two last culture media experiments, the $\beta$-galactosidase activity was reduced by only $65 \%$ with respect to the wild-type strain [7]. The $35 \%$ of remnant activity suggested that other regulators besides $\mathrm{NtrC}$ might be participating in the synthesis of PchP, but this point has not yet been resolved.

However, experiments with choline or dimethylglycine as carbon and nitrogen sources by $P$. aeruginosa PAO1 $\mathrm{P} 1::$ lac $Z$ showed the rapid response of the promoter during the beginning of the lag phase of growth; the production of $\beta$-galactosidase activity, at the maximum point, was approximately $50 \%$ higher in dimethylglycine medium than in choline medium [16]. These results together with findings from other laboratories $[5,6]$ demonstrated that GbdR and $\mathrm{CbrB}$ are indispensable for choline metabolism when it was the carbon source. In addition, GbdR and NtrC are necessary for the expression of PchP; dimethylglycine is likely the metabolite directly involved in the induction of PchP. Therefore, the regulation of choline metabolism and consequently PchP synthesis may reflect an adaptive response of $P$. aeruginosa to environmental conditions. This is in line with some results described in P. fluorescens, where a similar pattern of regulation for the catabolism of certain amino acids (histidine, proline, leucine, isoleucine, and valine) is also controlled by $\mathrm{CbrAB}$ and NtrBC. The specific induction of enzymes involved in their metabolism is indispensable in the presence of the specific substrate [13].

In order to explain the participation of specific regulator GbdR and the global regulators $\mathrm{NtrBC}$ and $\mathrm{CbrAB}$ in the synthesis of PchP, we first focused our attention on the transcriptional organization of the $p c h P$ gene [7]. Bioinformatic predictions, confirmed experimentally by site-directed mutagenesis and transcriptional fusion analyses, led to the conclusion that full $p c h P$ expression depends on an upstream region located -188 to $-68 \mathrm{bp}$ from the ATG start codon. Although this sequence has a score below the best prediction for a $\sigma^{54}$-dependent promoter, it contains (i) the conserved $-24 \mathrm{GG}$ and $-12 \mathrm{GC}$ elements characteristic of putative $\sigma^{54}$-dependent promoters, (ii) a region that resembles an IHF binding site, and (iii) a potential EBP binding site resembling the palindromic NtrC-binding consensus site $[17,18]$. The dependence of $p c h P$ expression on the $\sigma^{54}$ factor was confirmed using a $\Delta r p o \mathrm{~N}$ mutant strain, which showed a strong reduction in expression $(\cong 70 \%)$. On this point, we assumed that the residual expression may result from a second promoter that could be activated by GbdR. Because the upstream region of PA5380 ( $g b d R)$, as analyzed by PromScan software, has a high similarity score (86 out of 100) with $\sigma^{54}$-dependent promoters, we suggest that a cascade of events happen when choline is the alternative source of carbon, nitrogen, or carbon and nitrogen; (i) $\mathrm{NtrB}$ and CbrA respond to the absence or deficiency of the preferred carbon or nitrogen sources. (ii) These sensors activate, through phosphorylation, the respective response regulators $\mathrm{NtrC}$ and $\mathrm{CbrB}$, which are enhancers of $\sigma^{54}$ dependent promoters. (iii) As choline is an alternative carbon and nitrogen sources for growth, all genes involved in its catabolism or related to choline catabolism, for example, $g b d R$, $p c h P$ (and some other) are first activated. (iv) Once the intracellular concentration of GbdR increased, the enzymes of choline catabolism are directly activated [6] and specifically interact with the $p c h P$ promoter near the -12 box [5]. This interaction may move the $\sigma^{54}$ - polymerase from the promoter, so transcription from other promoter sequences can occur. In conclusion, we are only beginning to understand this activity because pchP expression now appears much more complex than previously anticipated, suggesting that more than one form of RNA polymerase and multiple transcriptional regulators could be involved.

\section{Bioinformatic Studies}

Initial bioinformatics studies indicated that PchP belongs to the haloacid dehalogenase hydrolase (HAD) superfamily. According to the following reference [[24], (http://www. ncbi.nlm.nih.gov/Structure/cdd/cddsrv.cgi)], “The haloacid 


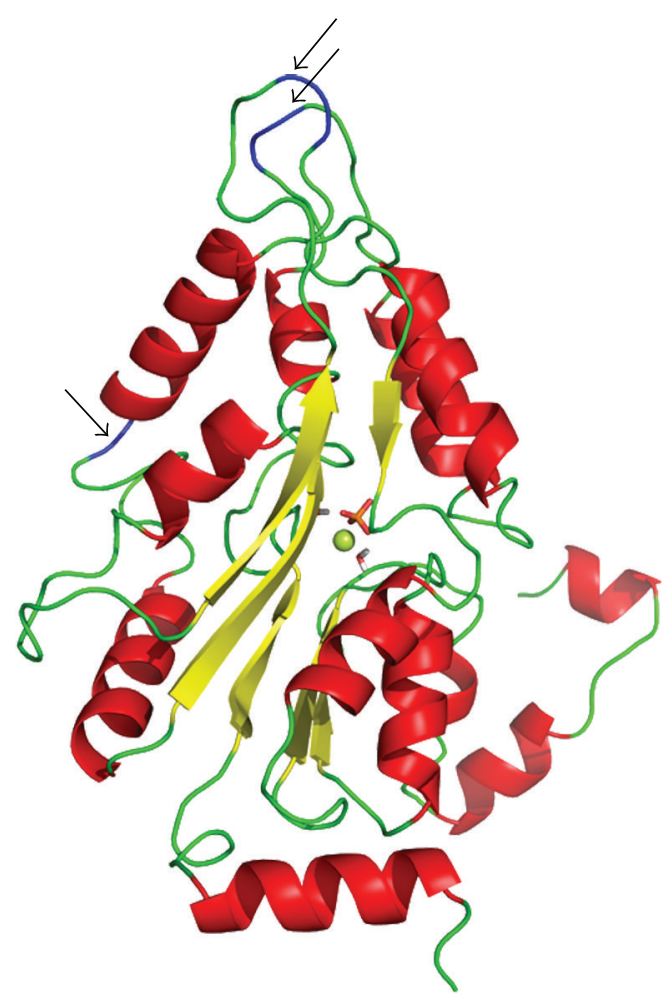

(a)

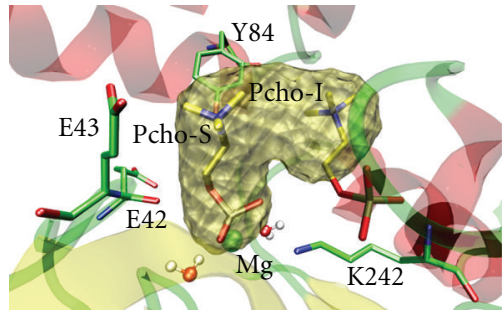

(b)
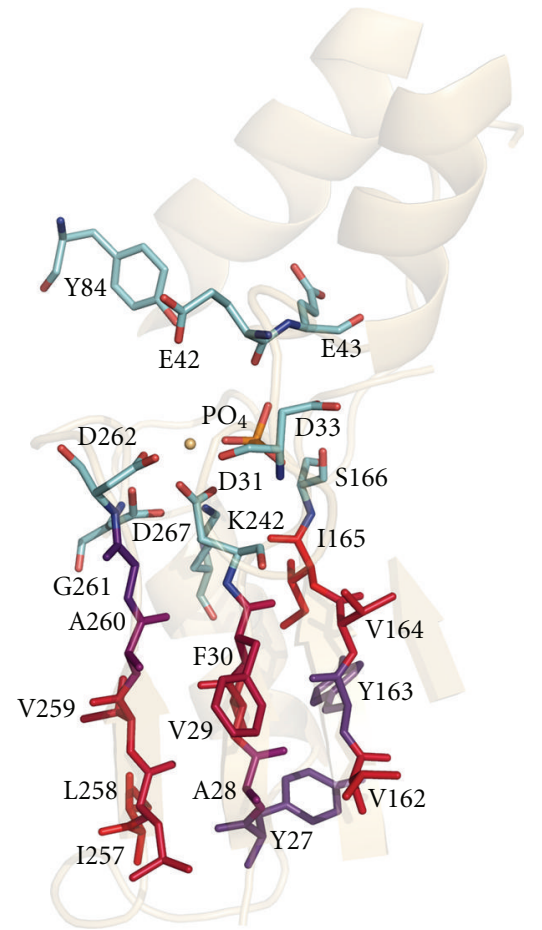

(c)

Figure 1: Model of PchP. (a) Cartoon representation. The points where loops were eliminated for modeling are indicated by an arrow. (b) A model of PchP representing the pocket detected by ICM-Pro and two conformations of Pcho. Cartoon representation of the secondary structure, stick representation of certain residues and Pcho, and msms (solvent excluded surface) representation of the pocket. Pcho-S: substrate conformation, Pcho-I: inhibitor conformation. (c) Stick representation of residues from the active site of members of the HAD superfamily, plus the hydrophobic pocket surrounding the active site. The residues of the active site are colored by element, and the rest are colored by hydrophobicity according to the Kyte and Doolittle scale [14], in which the most hydrophobic residues are red, and the most hydrophilic are blue.

dehalogenase-like superfamily includes L-2-haloacid dehalo genase, epoxide hydrolase, phosphoserine phosphatase, phosphomannomutase, phosphoglycolate phosphatase, P-type ATPase, and many others, all of which use a nucleophilic aspartate in their phosphoryl transfer reaction. All members possess a highly conserved alpha/beta core domain, and many also possess a small cap domain, the fold and function of which is variable. Members of this superfamily are sometimes referred to as belonging to the DDDD super-family of phosphohydrolases." The pchP gene published in the Pseudomonas genome database $V_{2}$ indicates that it codes for a protein containing 349 amino acids. However, because PchP is exported to the periplasmic space, it produces a mature protein containing 327 amino acids. Therefore, motifs I, II, and III, which are characteristic of enzymes belonging to the HAD superfamily, are found at ${ }^{31} \underline{\mathrm{D} M} \underline{\mathrm{D} N T^{35}},{ }^{166} \mathrm{~S}$, and ${ }^{242} \mathrm{~K} /{ }^{261} \mathrm{G} \underline{\mathrm{D} T P D S} \underline{\mathbf{D}}^{267}$ (the aspartyl residues involved in the catalysis of PchP are denoted in bold and underlined) $[25,26]$.

3.1. Molecular Modeling. As previously indicated [24], all members of the HAD superfamily share a similar catalytic mechanism that uses a nucleophilic aspartate, but the overall homology among these enzymes is small. Their sequence identity is less than $15 \%$ and is focused on three short motifs that form the active site [27]. In previous modeling studies of PchP, threading techniques were employed using the Methanococcus jannaschii phosphoserine phosphatase atomic coordinates as a template (mjPSP, PDB code 1F5S) [28]. This model was very useful for determining the catalytic relevance of the residues in the active site and for the description of phosphate and $\mathrm{Mg}^{2+}$ binding $[25,26]$. However, the template was much shorter than PchP, and 3d-pssm did not model several regions; consequently the final PchP model was segmented. These problems required major improvements to the model to allow the use of a docking approach to make advances in determining the quaternary ammonium-binding site. Therefore, a strategy was implemented combining protein fold recognition and comparative modeling by satisfaction of spatial restraints. First, the PchP sequence (lacking the signal peptide) was submitted to the PHYRE server [29], which is a more accurate and updated version of $3 \mathrm{~d}$-pssm. This server performs alignments with proteins of known structure according to sequence identity, secondary structure as predicted by PSIPRED, and solvent accessibility. The best-ranked template was phosphoserine phosphatase from $M$. jannaschii, with 


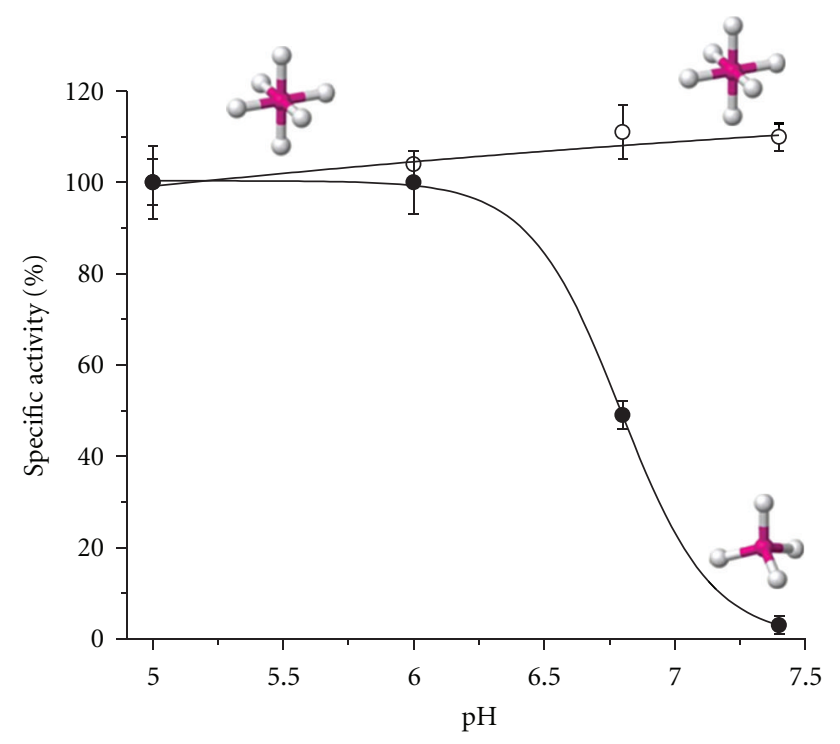

Figure 2: Effect of $\mathrm{pH}$ on PchP activity in the presence of $10 \mathrm{mM}$

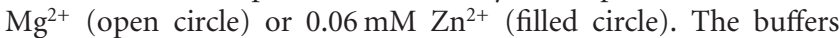
used were $100 \mathrm{mM} \mathrm{HAc} / \mathrm{NaAc}, \mathrm{pH}$ 5.0, $100 \mathrm{mM} \mathrm{HAc/KAc,} \mathrm{pH} \mathrm{6.0,}$ $50 \mathrm{mM}$ Hepes/NaOH, pH 6.8, and $50 \mathrm{mM}$ Hepes/ $\mathrm{NaOH}, \mathrm{pH}$ 7.4. Insert shows the coordination sphere for each metal.

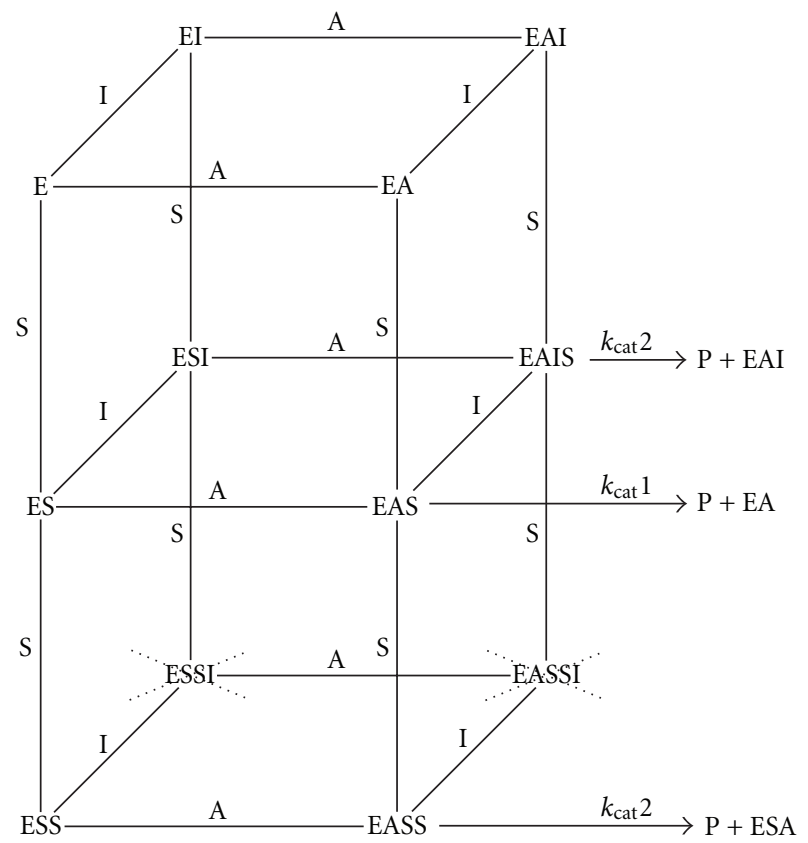

Figure 3: Scheme of the catalytic mechanism of PchP in the presence of metal ion (A), Pcho (S), and AAC (I). All reactions that occur in the cubes are reversible. Different true $K_{\mathrm{M}}, K_{\mathrm{A}}, K_{\mathrm{I}}$, $K_{\mathrm{SI}}$, and $k_{\text {cat }}$ values are published elsewhere [15]. Kinetic data does not indicate that ESSI and EASSI complexes reformed.

$100 \%$ confidence, but once again, template size was a problem. While mjPSP has 222 residues, PchP has 327; this results in regions without a template for PchP modeling. In addition, the secondary structure predicted for those regions was coiled and formed large loops. Therefore, it was not possible to model those loops with an acceptable level of accuracy, and those regions were discarded for the next step (residues 56-67, 120-136, and 206-224). This edited alignment was the input alignment for MODELLER. The final model was minimized and equilibrated using molecular dynamics, and the regions containing the three mega-loops that were eliminated (indicated by arrows) are shown in Figure 1(a). Like all members of the HAD superfamily, the model of PchP possesses an $\alpha / \beta$ core domain that consists of a central parallel $\beta$-sheet flanked by $\alpha$-helices on both sides. The catalytic scaffold is located in this central core, which is composed of four loops. Loop 1 contains the nucleophilic aspartate, loops 2 and 3 contain the serine from motif II and the lysine from motif III, respectively, and loop 4 contains the two aspartate residues of motif III involved in metal coordination. Despite the absence of the three megaloops, the new model was significantly improved compared to the previous one [25] and allowed docking studies to be performed in the active site region.

3.2. Docking Assays. Docking studies with Pcho performed with wild-type PchP (wtPchP) only showed one major conformation for the substrate regardless of whether the entire protein or only the HAD pocket was mapped (Figure 1(b)). The alternative conformations were very similar, with only slightly modified rotation angles. The presence of two interaction sites for Pcho in PchP was measured in crude extracts [30] and in the purified enzyme [3], and attention was focused on finding an explanation for this observation. A second conformation of Pcho was detected when the docking study was performed with the wtPchP-Pcho complex obtained after the first docking. A second molecule of Pcho was docked into the pocket at its alkylammonium moiety in an empty zone of the pocket (Figure 1(b)). The binding energy of the second conformation was found to be much higher $\left(-75.5 \mathrm{Kcal} \mathrm{mol}^{-1}\right.$ versus $\left.-4.9 \mathrm{Kcal} \mathrm{mol}^{-1}\right)$, indicating that the substrate first binds in the catalytic position with high affinity, and only when this site is occupied is a second molecule of substrate able to bind into the pocket in an inhibitory conformation. The inhibitory conformation of the substrate may block the entry and/or exit of the substrate and products; the enzyme-substratesubstrate complex can be productive, but with much lower efficiency. This result explains the inhibition caused by high concentrations of substrate. Considering the pocket shape detected by ICM-Pro, as well as the kinetic and docking results, we hypothesized that the binding pocket is composed of a catalytic site (with a subsite for the phosphate moiety and a subsite for the alkylammonium moiety) together with an inhibitory site capable of recognizing the alkylammonium moiety of Pcho (or another $\mathrm{NR}_{4}{ }^{+}$group) (Figure 1(b)). Therefore, it appeared likely that different alkylammonium compounds (AACs) could bind to both sites. Kinetic experiments seemed to confirm this possibility (the data are discussed at the end of the next section).

\section{Biochemical Studies}

PchP was discovered as an acid phosphatase (AcPase) whose activity, measured with $p$-nitrophenylphosphate ( $p$-NPP) in 

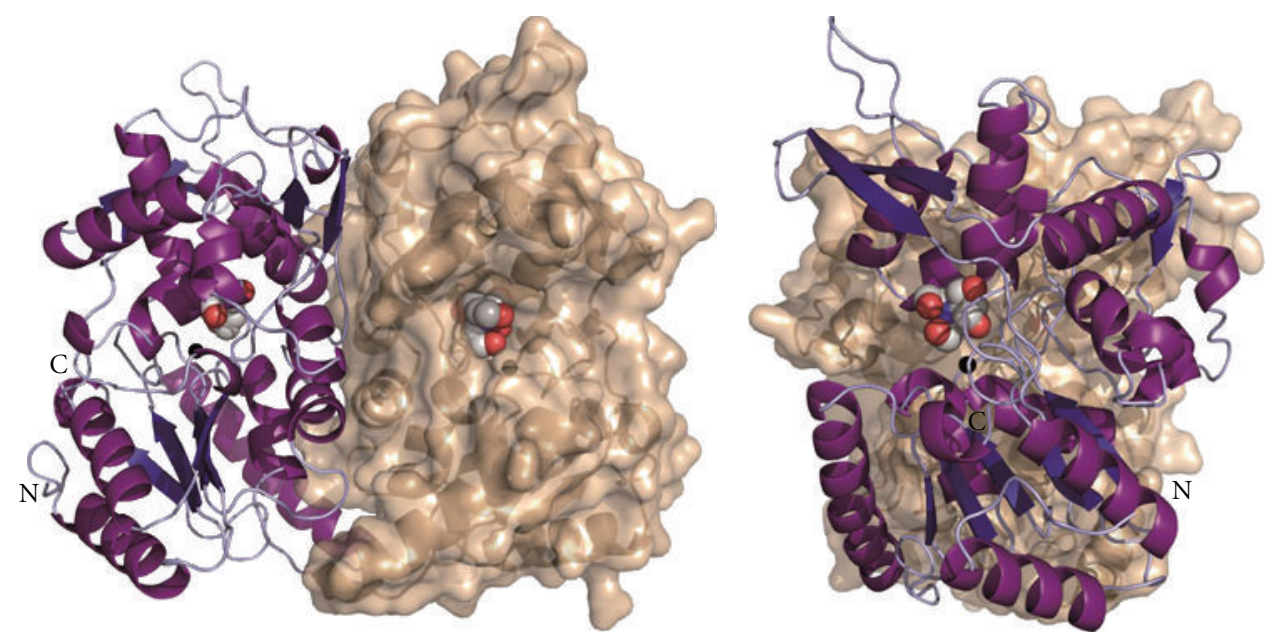

FIgURE 4: Two perpendicular views of a ribbon representation of the dimeric PchP crystallographic structure. The atoms at the active site are displayed in a spherical mode. The preparation of the figure from crystallographic data was performed by Lourdes Infantes and Armando Albert from IQFR-CSIC, Madrid, Spain.

the presence of $\mathrm{Mg}^{2+}$ at $\mathrm{pH} 5.0$, is inhibited by choline, betaine, acetylcholine, Pcho, and many AACs $[8,9,15]$. These unusual acid phosphatase characteristics, measured in the laboratory $[8,31]$ or described by other authors [32$36]$, led to the proposal that the AcPase produced by $P$. aeruginosa grown in the presence of choline or derivative metabolites is capable of catalyzing the hydrolysis of $p$-NPP, Pcho, and phosphoethanolamine [3]. Remarkably, the optimum $\mathrm{pH}$ (measured in the presence of $\mathrm{Mg}^{2+}$ ) depends on the substrate used; it is approximately 5.0 and 6.0 for $p$ NPP and phosphoethanolamine, respectively. The optimal $\mathrm{pH}$ range for Pcho was found to have a plateau between 5.0 and 8.0 [3]. Considering these data and the fact that PchP acts in the periplasmic space (a compartment where the $\mathrm{pH}$ may vary according to environmental conditions) [37], kinetic properties, including saturation by substrate, activation by divalent cations, and inhibition by AACs, were studied with Pcho as the substrate at pH 5.0 and 7.4, and with $p$-NPP as the substrate at $\mathrm{pH} 5.0$ (with this latter substrate, there is no enzymatic activity at $\mathrm{pH}$ 7.4). The first studies were performed with a recombinant enzyme, initially as an intein fusion $[4,25,26]$ and later with the enzyme expressed with a histidine tag [38]. The catalytic importance of the aminoacyl residues on motifs, I, II, and III was shown through site-directed mutagenesis of the aspartyl $\left({ }^{31} \mathrm{D},{ }^{33} \mathrm{D}\right)$ and threonyl $\left({ }^{35} \mathrm{~T}\right)$ residues of motif I, of the seryl $\left({ }^{166} \mathrm{~S}\right)$ residue of motif II, and of the lysyl $\left({ }^{242} \mathrm{~K}\right)$, glycyl $\left({ }^{261} \mathrm{G}\right)$, and aspartyl residues $\left({ }^{262} \mathrm{D},{ }^{265} \mathrm{D}\right.$, and ${ }^{267} \mathrm{D}$ ) of motif III (Figure 1(c)) [25]. By comparison with the phosphoserine phosphatase of $M$. jannaschii $[28],{ }^{31} \mathrm{D}$ is phosphorylated during phosphoester hydrolysis, and the oxygen atom of the carboxyl group of ${ }^{31} \mathrm{D}$ may be involved in nucleophilic attack on the phosphorus atom of the substrate (either $p$-NPP or Pcho). The ${ }^{33} \mathrm{D}$ residue is important for catalysis because it participates in the phosphorylation of ${ }^{31} \mathrm{D}$. Considering the motif III residues ${ }^{262} \mathrm{D},{ }^{265} \mathrm{D}$, and ${ }^{267} \mathrm{D}$, it has been shown that ${ }^{262} \mathrm{D}$ and ${ }^{267} \mathrm{D}$ are the aspartyl residues involved in catalysis. Additionally, it has been shown that the positively charged group of lysyl residue ${ }^{242} \mathrm{~K}$ is necessary to stabilize the negative charge of the phosphate [25]. After confirming the residues that interact with phosphate and magnesium, we focused our interest on the interaction with the choline moiety of the substrate. This approach was based on comparison to the human enzyme PHOSPHO1 (a phosphocholine/phosphoetanolamine phosphatase also belonging to the HAD superfamily) [39], PHOSPHO2 [40], and choline binding proteins of Gram $(+)$ bacteria [41]. We selected residues ${ }^{42} \mathrm{E},{ }^{43} \mathrm{E}$, and the aromatic triplet ${ }^{82} \mathrm{YYY}^{84}$ as possible candidates to interact with Pcho and $p$-NPP. Using a comprehensive approach including homology modeling, site-directed mutagenesis, and kinetic and docking studies, we show that the residues mentioned above interact differently with Pcho and $p$-NPP. We found that ${ }^{43} \mathrm{E}$ of $\mathrm{PchP}$ is critical for the distinctive inhibition produced by high concentrations of Pcho and that the absence of the side chain in that position makes PchP a more efficient acid phosphatase. ${ }^{42} \mathrm{E}$ has relevance in substrate recognition because its substitution with alanine decreased activity with $p$-NPP but increased activity with Pcho. Because mutations in residues ${ }^{43} \mathrm{E}$ and the three tyrosines affect both the affinity for substrate and the inhibitory effect for high levels of Pcho, we believe that both a catalytic and regulatory site are present in PchP and that they are near each other in space and even share residues [42]. After identifying the catalytic pocket of PchP through kinetic experiments and developing a single structural model $[25,26]$, the interactions of the phosphate moiety with the activating metal ions $\mathrm{Mg}^{2+}, \mathrm{Zn}^{2+}$, and $\mathrm{Cu}^{2+}$ were investigated [26]. The first results obtained with the recombinant enzyme confirmed previous findings $[3,43]$. The new results indicated that at $\mathrm{pH} 5.0$, with $p$ NPP plus suitable concentrations of different metal ions, the activity of PchP measured in the presence of $\mathrm{Zn}^{2+}$ or $\mathrm{Cu}^{2+}$ was higher compared to that with $\mathrm{Mg}^{2+}$. Classic kinetic experiments such as saturation curves with substrate or 


Gzea
Nhae
Ggra
Pter
Ptri
Lmac
Mory
Valb
Pent
Pput
Pflu
Psyr
Paer
Bamb
Bcen
Bmul
Lnit
Asp

Gzea
Nhae
Ggra
Pter
Ptri
Lmac
Mory
Valb
Pent
Pput
Pflu
Psyr
Paer
Bamb
Bcen
Bmul
Lnit
Asp

Gzea
Nhae
Ggra
Pter
Ptri
Lmac
Mory
Valb
Pent
Pput
Pflu
Psyr
Paer
Bamb
Bcen
Bmul
Lnit
Asp

Gzea
Nhae
Ggra
Pter
Ptri
Lmac
Mory
Valb
Pent
Pput
Pflu
Psyr
Paer
Bamb
Bcen
Bmul
Lnit
Asp

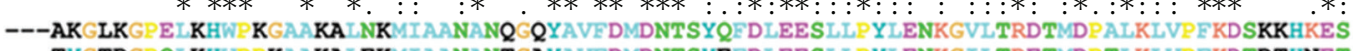
---TYGTR GP KHWP K KA KA EKMIAANANT TAYAVEDMDNTSYEDLEESLIPYLENKGILTRETMDPTKLVPEKDTDTHNET -YASNHTA GP E KHWP AEA.KA NTMIAANANQSNYAVEDMDNTSWHY IEESMLPFLENKKVISRDTMD SLKLIPFKDTANYTES ---QYGTAKTQI KHWP AEAA TA NRMIARNANQSNYACEDMDNTSYRYDIEESLIPFL DNRGILTREKLDPLKLIPFKDTAN TES ---HYGTAKTQ KHWPAEAATANRIARNANQSNYACFDMNTSYRYDIEESLIPFL DNRGILTREK DP SLKLIPFKDTAN TES ---SCGTSTT QHWP ADAAK NAMIA KNANQSNYAVEDMDNSYRYDLEESLLPFLENRGILTREK D SLKUID KDTAN TES ----VTTNSTM SHW SA TS EA KRN HT AYAAFD DNTSWREDVEESLIPY DNKGVISRDK D SLKITPFKDTATYKES

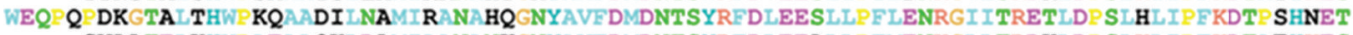
-SWAATE KHWP AEAAK Q DAMIAANANK GNYAVFDMDNTYREDLEEA LPFMENKGLITRDK D SLKLIPEKDTAEHKS -TFA-TEL KHWP ADAA KQ DSMIAANANKGNYAVEDMDNTSYRYDLEEALIPFMENKGLISRDK DP SLKLMPFKDTAEHKS -ALA-TE KHWP AEQ KQ DAMIAANANKGNYAVEDMDNSYRYDLEESLLPFMENKGLITRDTLDP SKLIPFKDTAEKES -AFAATO KHWP E RA DAMTAANANK GNYAVEDVDNTSYREDIEESLTPYMENKGLTTRETLD STKLTPFKDTAEHKES

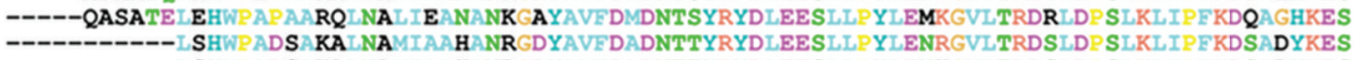

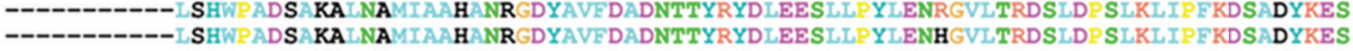
- AHWP ADS KA NA MIAA H HRGDYAVE DADNTTYRYDLEESLLPYLEHRGVLTRDTLDASLKLIPFKDSADYKES

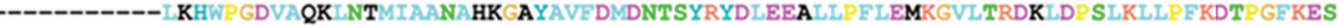

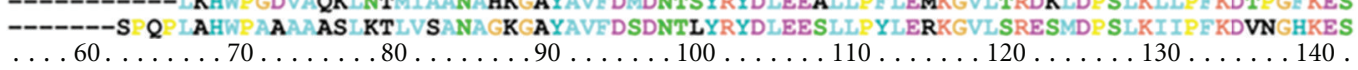

84

84

86
84

84

84

83

87
82

81

81

82
82

76
76

76

76
80

$: * * * * * *:::: * * * * * *:: * \quad * \quad * * \quad: *:::$

: $\quad:$. : $\quad * \quad:$ : $: * * * * * * * *$ :

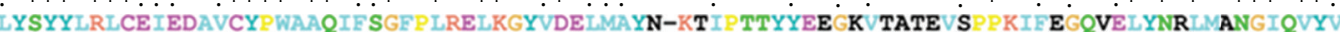
LYSYYNRLCEIEDAVCYPWAAQIF SGFP LRELKGYVDELMAIN-ETIPTTYFEDDK TAIDVS RIF EGOVELYNK LMNGIDVYV LYSYYNRLCDIDI VLCYPWAAQIF SGIP LIELKGYVDELMAIN-HT STTYYEGDV THDEINPPRPFP GQQELYNKLMNGIDVYI MYSYYNRLCEIDN ICYPWAAQVE SGETLRELKGWVDELM S N-TT IPTAYWDGDS VTTSINPPRIERGQVELYNA RENGISVYV MYSYYNRLCEIDNEICYPWAAQAF SGFTLRELKGWVDELMAIN-TTIPTAYWDNDTLVSTSINPPRIF RGQVELYNA TMENGIDVYV

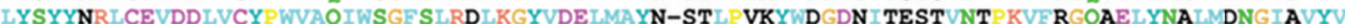
LYSYYSRICDIDAMVCYPWAAQVESGM KLREKGWVDELMT EGGIINTTQ VGNAVQNVS SR I R RQQLYNA DNGISVYV LF SYYYRLCEVDDLICYPWVAQVE SGTLRA KGYVDQLMAHN-GTIPTYFEGDVVT IA TNP RP RGQQELFNR RMENGIDVYI LFSYYYRICEIDDMVCYPWVAQVE SGETLKELKQQVDELMAS S-KPIP STYFEGDQ KTIEVQ RVE TGQAELYNK LMENGIEVYV LFSYYYRLCEIDDMVCY WVAQVE SGETLQELKAQVDELMAST-KP IP STYYEGDQVKAIE Q P KVE KGQAELYNK IMENGIEVYV TESYYYRI CETDDMVCYPWVA OVESGET KELKGYVDELMA S G-KPVP STYYD GDV KTIEVNPPKVE TGOAELYNK MENGIEVYV LESYYYRLCELDDMVCYPWVAQVE SGETLQELKGYVDELMAIK-KP IPATYYD GDT KQLN E PRVE TGQTELYNK LMENGIEVYV LFSYYYRLCEIDDMVCYPWVAQVE SGETLRELKGYVDELMAYG-KP IPATYD ADK ATLDVE RVE S GQRELYNK IMENGIEVYV LTSYYYRLCEIDDLVCYPWIAQAF A GLSI AD KRHVDA ILA G-KPVP IRYWQGDKVVD A NPPRFE RGMQELYNA RENGIEVYV LTSYYYRICEIDDLVCYPWIAQAF A QSIAD KRHIDA IAAG-KPIPIRYWQGDKVVD TVNPPREF RMQELYNA RENGIEVYV LTSYYYRICEIDDLVCYPWIAOAFAGLSI AD KRHIDA AI DG-KPIPIRYWOGDK VD T TNPPRER R MOELYNA RENGIEVYV INYYYRLCEVDDLVCYPWVAQVE SGETLKQLKGYVDELMAYD-KP IP IKYYS GDKVVEGTVNR RPYT MQELYNR QENGIEVYV INSYYYRLCEIDDQ VCYPWVAQIF SGFT AQLKS DEMLADG-KP IPATYYD GDAVKTVE S PRFYTGQQELVNHLTANGIEVYV

II

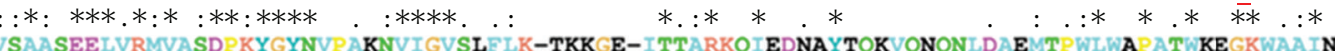
VSAASEELVRMVASD KYGYNVP AEKIGVTL MO-EKNGD-LTTARKOIEDGEYEKEIOOONLDAKTPELWA TW KAGWAAII

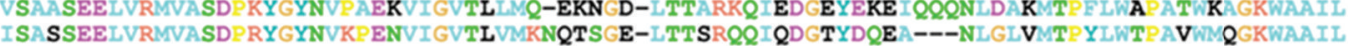
ISA SHEELVRMVASD KYGYNVP ONVIGVTTMLKNSTSGA-LTNARKOISAGTYNOT ---NLDLVVTPYLWTPATWYAGKWAAIL ISA SHEELVRMVASD KYGYNVP PNVIGVTTMLKNATSGA-LTNARKOIADDSYDOTA---NLDLVVTPYLWTPATWYAGKWAAIL ISAA HEELVRFVA SD KYGYNVP PNVIGVTTMI KNVTSGD-ITN RKOITEGIYDYE ---NLDIV TT YLWTPATWEAGKWAAII UT SNEELVRMVA SD KYGYNVP ANVIGVTTLI SNASD SN TTARKA EDGVD E ---FDTTT YLWT PTWM SGKYGAIL MTAASEELVRMVASD KYGYNVP KNVIGVTM AN AD SSPTTARKQIEA TYDEK ---NLDET TPYLWTPITWMAGKHAAIL ISAASEELVRMVA AD KYGYNVK ENVIGVSL LIKDRANGQ-LTTARKQITAGHYD K ---NEGLELTPYLWTPATWMAGKQAAIL VSAASEELVRMVASD KYGYNVK ONVIGVSL LLKDRASGQ-LTTARKQISAGHYDAK---NEGLELTPYWTPATWMAGKQAAIL

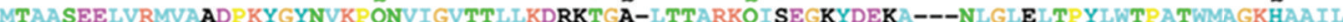
MTAASEELVRMVA AD KYGYNVK QNVIGVTTLLKDRKTGE-LTTARKQITAGKYDAKS---NMGLETPYLWTPATWMAGKQAAIL ISAAHEELVRMVA AD RYGYNAKP ENVIGVTTLLKNRKTGE-LTTARKQIAEGKYD K ---NLDIEVTPYLWTPATWMAGKQ AAIL MTAAHEELARLVLSD KYGYNVK QNVIGVTTLLRN ATGA-LTTSRLQIKAGKYDEA---NRNLVITPFLMN NTWYEGKLGSIV MTAAHEELARLVI AD KYGYNVK QNVIGVTTLLRN ATGA-LTTSRLQIKAGKYDEA ---NRN VITPFLMN MTWYEGKLGS IV VTAA HEELARLVLSD KYGYNVK ENVIGVTTLIRN ATGT-LTTSRLOIKA KYDEA---NRN V TPELM N MTYEGKLGSIV VSAAGEELARMVVSD KYGYNVK QNVIGVNMLIKDRTSGE-LTSSRLQIKKGKYD AR---NLDIELTPYLMN NTWYEGKLGSIV

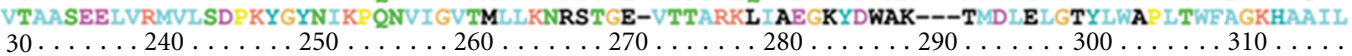

$$
\text { III }
$$

TYIDT WKRPIIAGGDT DSDGPMT RGVNVERGGIHLWVDRK AYREOTDGMTKNYT AOKEOK PVTANKNWVEVT NEI HDA TYIDEWKK ILA A GT DSD GPMIFHGVDVKKGGIHLWVDRKESYSKOIRGMI SDF KAOKKEGLPVTADKNWVMVK AD HGE TYIDEWKKPVLAGGDT ISD GPMIEHGVDVAKGGIHLWINRKDSYMEQNE MI KNNTAAQKREGLPVTADKNWVIVT EDIE-TYISEWKR VLVGGDTP GSDTYM Q HGVDVGKGGVHLWINRTQAVYEK EKE KENTEEOKREGREVTADKNWVVVKPEEIL-TY SEWKR ILVGGDT GSDTYM Q HGVDVGKGGVHLWINRTAAVYEK EKEI KEN EEQRANGREVTADKNWVVVKPEEIL-TYIDEWKI IF A ADT GSDS FIFHGVDTAKGGVHLWINRRDAYIER O E KNNT AOIANGREVTADKNIFVK AD L-TYISOWRKAVLVA GDT DSD GYMIFHDVDVAKGGVR WINKKOSN DOIOGMTANNTI EOASLGOEVTADKNWVIVKPEETL-TYISQWKK VLVGGDT TSD GYMLFHDVDVWKGGVRVWVDRKASYRTQIDGMIKDN DQQRKL GLPVTADQNWIKVKPEIL-TYIDEWKKPVLVGGDT TSD GY Q F SVDVGKGGIHLWINRKAKYMDQINGMIAKHAAAQAKEGLPVTADKNWVIVT EQIQ-TYIDEWKKPVLVGGDT TSDGY Q HGVDVGKGGIHLWINRKAKYMDQINGMIAKNAAQAKEGLPVTADKNWVIVT EQIQ-TYTDEWKKPVLVGGDT TSD GYMIFHDVDVAKGGIHLWINRKDKYM TOINGMTAKH AOAKEGLPVTADKNWVIVKPEDIO-TYIDOWKK PVVGGDT TSD GYMLFHS DVSKGGVHLWINRKDKYMTOINGMI KAN EAOAKEK PVTADKNWVIVKP DEIO-TYIDR WKR ILVA GDT DSD GYMLE N--GTAEN GVHLWVNRKAKYMEQ INGMI KQHS AQAKA GLPVTADRNWVIVT EQIQ-GWIDQWKKPVLVA GDTP TSD GYMLINATDVARGGVRVWVNKKDKQ AQIRA WSDESA.KOKALGLPVTADKNWIVVRPAIQ-GWIDQWKKPVLVA GDT TSDGYMLINATDVARGGVRVWVNKKDKQ AQIRA SDES KOKSLGLPVTADKNWIVVK DAIQ-GWIDQWKKPVLVA GDT ASD GYMLINATDVARGGVRVWIDKKDKQ AOIRA SDES KOKALGLPVTADRNWIVVK DAIO-GWIDQWKK VLVGGDT ISD GYMLINSTDVEKGGVRVWVNRKAKYMP A QSWWES KRQASL QTVTADKNWLVVKPEDIQ--

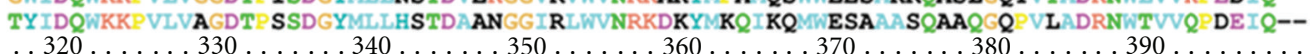

(a)

Figure 5: Continued.
170 


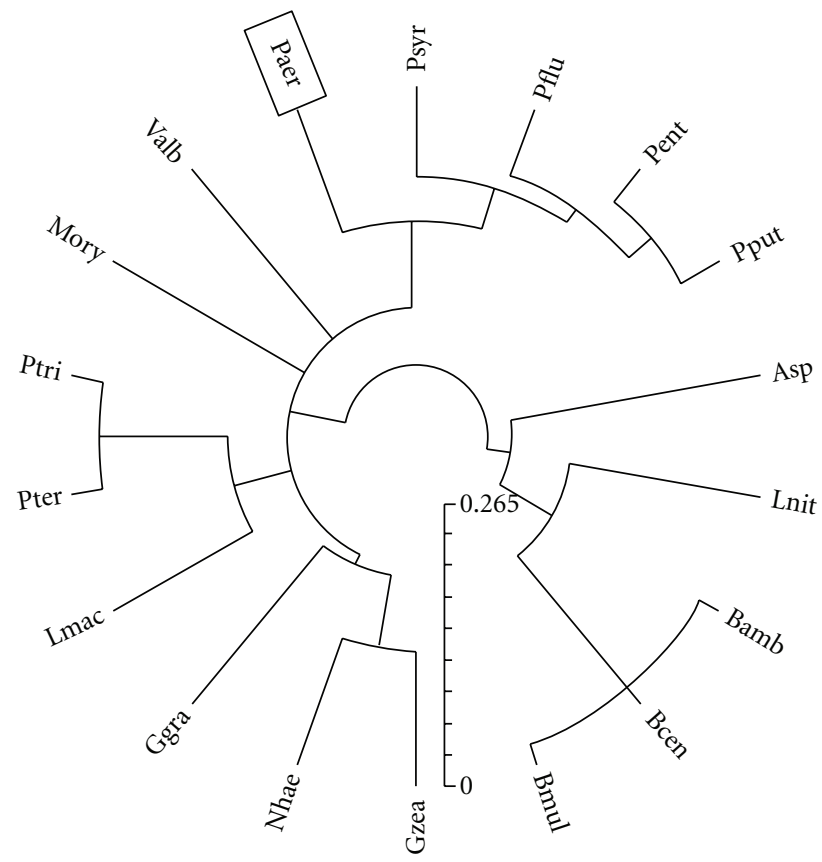

(b)

Figure 5: (a) Amino acid sequence alignment of PchP with proteins from different organisms. The sequences analyzed were as follows: Paer, Pseudomonas aeruginosa PAO1; Psyr, Pseudomonas syringae pv. tomato str. DC3000; Pflu, Pseudomonas fluorescens Pf-5; Pent, Pseudomonas entomophila L48; Pput, Pseudomonas putida KT2440; Asp, Azospirillum sp. B510; Lnit, Lutiella nitroferrum 2002; Bamb, Burkholderia ambifaria MC40-6; Bcen, Burkholderia cenocepacia MC0-3; Bmul, Burkholderia multivorans ATCC 17616; Gzea, Gibberella zeae PH-1; Nhae, Nectria haematococca mpVI 77-13-4; Ggra, Glomerella graminicola M1.001; Lmac, Leptosphaeria maculans; Pter, Pyrenophora teres f. teres 0-1; Ptri, Pyrenophora tritici-repentis Pt-1C-BFP; Mory, Magnaporthe oryzae 70-15; Valb, Verticillium albo-atrum VaMs.102. The alignment was constructed using the program CLUSTAL-X [19]; $(*)$ indicates identical residues, (:) indicates conserved residues, and (.) indicates semiconserved residues. The three catalytic motifs of the HAD superfamily are marked in red. (b) Evolutionary relationships of 18 taxa (linearized). The evolutionary history was inferred using the neighbor-joining method [20]. The optimal tree with the sum of branch length $=2.68745267$ is shown. The phylogenetic tree was linearized assuming equal evolutionary rates in all lineages [21]. The clock calibration to convert distance to time was 0.002 (time/node height). The tree is drawn to scale, with branch lengths in the same units as those of the evolutionary distances used to infer the phylogenetic tree. The evolutionary distances were computed using the Poisson correction method [22] and are in units of amino acid substitutions per site. All positions containing gaps and missing data were eliminated from the dataset (complete deletion option). There were a total of 338 positions in the final dataset. Phylogenetic analyses were conducted in MEGA4 [23].

metal ions led to the conclusion that with the p-NPP substrate, the catalytic efficiency of $\mathrm{PchP}$ activated by $\mathrm{Zn}^{2+}$ is approximately 2.5 - or 3.2-fold more efficient than with $\mathrm{Cu}^{2+}$ or $\mathrm{Mg}^{2+}$, respectively. The $K_{\mathrm{M}}$ value of $p$-NPP was found to be identical when the enzyme was measured with $\mathrm{Mg}^{2+}$ or $\mathrm{Zn}^{2+}$ but increased approximately 3.5 -fold in the presence of $\mathrm{Cu}^{2+}$. However, the $K_{\mathrm{A}}$ value indicated that $\mathrm{Zn}^{2+}$ and $\mathrm{Cu}^{2+}$ have higher affinity than $\mathrm{Mg}^{2+}$ for the metal site of PchP $\left(0.01 \mathrm{mM}, 0.02 \mathrm{mM}\right.$, and $0.6 \mathrm{mM}$ for $\mathrm{Zn}^{2+}$, $\mathrm{Cu}^{2+}$, and $\mathrm{Mg}^{2+}$, resp.) [26]. These results with wtPchP led to experiments designed to obtain kinetic parameters with different mutants. Although different catalytic constants were obtained, no appreciable difference with respect to the activation produced by different divalent cations was detected. Other divalent cations such as $\mathrm{Mn}^{2+}, \mathrm{Co}^{2+}$, and $\mathrm{Cr}^{2+}$ (experiments were performed in strict conditions to avoid the oxidation of $\mathrm{Cr}^{2+}$ to $\mathrm{Cr}^{3+}$ ) also activated acid phosphatase activity. The results obtained by replacing $\mathrm{Zn}^{2+}$ with $\mathrm{Co}^{2+}$ will be useful for the study of different physicochemical properties through the utilization of electronic spectroscopy of $\mathrm{Co}^{2+}$-PchP derivatives. The catalytic site of PchP lacks both histidine and cysteine, two amino acids that contribute nitrogen or sulfur atoms to coordination complexes in many $\mathrm{Zn}^{2+}$ - or $\mathrm{Cu}^{2+}$-dependent enzymes that generally form tetrahedral or square planar complexes, respectively [44-47]. The utilization of the METALDETECTOR program [48] also indicated that the probability that either histidine or cysteine bound to the metal ion was very low (less than 10\% [49]). After this information our focus was placed on the idea that $\mathrm{Zn}^{2+}, \mathrm{Cu}^{2+}$, and $\mathrm{Mg}^{2+}$ may form octahedral coordination complexes with the oxygen atom of the carboxylic group of aspartic acid and the main chain carbonyl oxygen. Therefore, we concluded that the three metal ions form an octahedral complex with electron pairs from six oxygen atoms from the two -COO-, one $\left(\mathrm{O} \delta_{1}\right)\left({ }^{31} \mathrm{D}\right)$, one $\left(\mathrm{O} \delta_{2}\right)\left({ }^{262} \mathrm{D}\right)$, one carbonyl $\left({ }^{33} \mathrm{D}\right)$, one phosphate $\left(\mathrm{O}_{1}-\mathrm{P}\right)$, and two water molecules $[25,26,38]$. All of these donor groups are Lewis bases, and the metal ions are Lewis acids. Pearson $[50,51]$ introduced the concept of "hardness," $(\eta)$ "The nonchemical meaning of the word "hardness" is resistance to deformation or 
change;" this concept is useful for explaining the reasons why $\mathrm{Cu}^{2+}$ and $\mathrm{Zn}^{2+}$ are better activators than $\mathrm{Mg}^{2+}$. Chemically speaking, "hardness is resistance of the chemical potential to change in the number of electrons" [52]. This author also introduced the concept of chemical hardness and softness in connection with the behavior of Lewis acids and bases, adding, "hard acids prefer to coordinate to hard bases and soft acids to soft bases." Therefore, an acid with hardness $\eta_{\mathrm{A}}$ would prefer to bind to a base with similar hardness, $\eta_{\mathrm{B}}$. In our case [26], $\mathrm{Mg}^{2+}$ is a hard acid $\left(\eta_{\mathrm{A}}=32.5\right)$, whereas $\mathrm{Zn}^{2+}$ and $\mathrm{Cu}^{2+}$ have intermediate values (with $\eta_{\mathrm{A}}$ values of 8.3 and 10.8 , resp.) [52]. The hardness parameters $\left(\eta_{\mathrm{B}}\right)$ for Lewis bases participating in octahedral complexes are approximately 6 to 7 . Because these values are closer to the hardness values of $\mathrm{Zn}^{2+}$ and $\mathrm{Cu}^{2+}$ and are supported by kinetic data, we conclude that it is easier for these metal ions to form coordination complexes in the active site of PchP than for $\mathrm{Mg}^{2+}$. Next, the catalytic mechanism of PchP was studied; $\mathrm{Cu}^{2+}$ was discarded for simplicity, and the following experiments were performed with $\mathrm{Mg}^{2+}$ and $\mathrm{Zn}^{2+}$. The catalytic constant $\left(k_{\text {cat }}\right)$ values with $p$-NPP [53] or Pcho [15] as substrates were found to be 1.7- and 1.2-fold higher for $\mathrm{Zn}^{2+}$ than for $\mathrm{Mg}^{2+}$, respectively. The experiments were performed at pH 5.0 (in acetate buffer) and pH 7.4 (in Hepes buffer) because with Pcho as the substrate and $\mathrm{Mg}^{2+}$ as the activator, the optimal $\mathrm{pH}$ is a plateau between 5.0 and 8.0 [3]. The first experiments, which were needed to set experimental conditions for the following kinetic studies, were surprising. With $\mathrm{Mg}^{2+}$, the same enzymatic activity was measured at $\mathrm{pH}$ 5.0 and 7.4. With $\mathrm{Zn}^{2+}$, pronounced activity was found at $\mathrm{pH}$ 5.0, but no activity was detected at $\mathrm{pH} 7.4$ (Figure 2). We next focused on this lack of PchP activity with $\mathrm{Zn}^{2+}$ at neutral or alkaline $\mathrm{pH}$ values. The model of the enzyme, including amino acids in the vicinity of motifs I, II, and III, was considered in addition to the ionization of different PchP active site groups involved in the ionization of Pcho and the possible hydrolysis of the metal ion [38]. The model presented in Figure 1(c) shows the hydrophobic amino acid residues located in the $\beta$-sheets motifs I $\left({ }^{27} \mathrm{YAVF}^{30}\right)$ and III $\left({ }^{257}\right.$ ILVA $\left.^{260}\right)$. These residues are responsible for creating an environment with a low dielectric constant $(\varepsilon)$ which according to Dudev and Lim [54] is necessary for the coordination of the metal ion. Kinetic results, obtained at $\mathrm{pH}$ 7.4 with saturated $\mathrm{Mg}^{2+}$ and low $\mathrm{Zn}^{2+}$ concentrations and analyzed with the simulator DYNAFIT [55], indicated that $\mathrm{Zn}^{2+}$ might bind to free PchP or PchP- $\mathrm{Mg}^{2+}$ complexes with the same affinity to form the nonproductive complex $\mathrm{E}-\mathrm{Zn}^{2+}$. In addition to this experiment, it has also been shown that inhibition produced by $\mathrm{Zn}^{2+}$ in the presence or absence of $\mathrm{Mg}^{2+}$ is reversible and dependent on the $\mathrm{pH}$ of the reaction. To explain the changes in activity with $\mathrm{Zn}^{2+}$ and without $\mathrm{Mg}^{2+}$, the ionization state of the enzyme was ruled out as a factor. However, we considered in detail the change of Pcho ionization due to the inactivation of $\mathrm{PchP}$ at $\mathrm{pH}$ 7.4. We considered the ionization of O-Pcho using the soft- ware [ACD, Inc. (http://www.acdlabs.com)] according to the equations

$$
\begin{aligned}
\mathrm{O}=\mathrm{P}(\mathrm{O}-\text { choline })(\mathrm{OH})_{2} & \\
& \rightleftarrows \mathrm{O}=\mathrm{P}(\mathrm{O}-\text { choline })(\mathrm{OH}) \mathrm{O}^{-}+\mathrm{H}^{+}, \quad \mathrm{p} K_{2} \cong 6.0
\end{aligned}
$$

$$
\begin{aligned}
\mathrm{O}=\mathrm{P} & (\mathrm{O} \text {-choline })(\mathrm{OH}) \mathrm{O}^{-} \\
& \rightleftarrows \mathrm{O}=\mathrm{P}(\mathrm{O} \text {-choline })(\mathrm{O})_{2}{ }^{=}+\mathrm{H}^{+}, \quad \mathrm{p} K_{3} \gg 8.0
\end{aligned}
$$

Equation (b) was discarded, and (a) was used. The Henderson-Hasselbalch equation $\left(\mathrm{pH}=\mathrm{pKa}+\log \left[\mathrm{A}^{-}\right] /[\mathrm{HA}]\right)$ was used for $\mathrm{pH} 5.0,7.4$, and $\mathrm{pH}$ was set to the $\mathrm{p} K_{2}$ value. According to (a):

at $\mathrm{pH} 5.0 ; 5.0=6.0+\log \left[\mathrm{A}^{-}\right] /[\mathrm{HA}]$ and results in the following: $\left[\mathrm{A}^{-}\right] /[\mathrm{HA}]=0.1$,

at $\mathrm{pH} 6.0 ; 6.0=6.0+\log \left[\mathrm{A}^{-}\right] /[\mathrm{HA}]$ and results in the following: $\left[\mathrm{A}^{-}\right] /[\mathrm{HA}]=1$,

at $\mathrm{pH} 7.4 ; 7.4=6.0+\log \left[\mathrm{A}^{-}\right] /[\mathrm{HA}]$ and results in the following: $\left[\mathrm{A}^{-}\right] /[\mathrm{HA}]=25$,

at $\mathrm{pH} 7.4$, the main ionic species $\left[\mathrm{A}^{-}\right]=[\mathrm{O}=\mathrm{P}(\mathrm{O}-$ choline $)$ $\left.(\mathrm{OH}) \mathrm{O}^{-}\right]$is approximately 250 times more concentrated than at $\mathrm{pH}$ 5.0. Under the assay condi-tions, this anion (free in solution or as a substrate bound to the enzyme) is neutralized by monovalent cations present in the reaction buffer $\left(\mathrm{Na}^{+}\right.$or $\mathrm{K}^{+}$at $\mathrm{pH} 5.0$ or 7.4). This is true when enzyme's activity is measured in the presence of $\mathrm{Mg}^{2+}$ or $\mathrm{Zn}^{2+}$. The protonation/deprotonation of $\mathrm{O}$-phosphocholine at different $\mathrm{pH}$ values does not change in the presence of $\mathrm{Mg}^{2+}$ or $\mathrm{Zn}^{2+}$. Therefore, it was assumed that the inhibition produced by $\mathrm{Zn}^{2+}$ is caused by an intrinsic property of this ion. The catalysis produced by PchP in the metal ion binding site to form either an octahedral complex $\left[\mathrm{Mg}^{2+} \mathrm{L}_{2}^{-1} \mathrm{~L}_{2}^{0}\left(\mathrm{H}_{2} \mathrm{O}\right)_{2}\right]$ or $\left[\mathrm{Zn}^{2+} \mathrm{L}_{2}^{-1} \mathrm{~L}_{2}^{0}\left(\mathrm{H}_{2} \mathrm{O}\right)_{2}\right]$ is formed by $\mathrm{Me}^{2+}$-two $\mathrm{COO}^{-}$(provided by ${ }^{31} \mathrm{D}$ and ${ }^{262} \mathrm{D}$ residues), -one $\mathrm{C}=\mathrm{O}$ (provided by ${ }^{33} \mathrm{D}$ ), -one $\mathrm{O}=\mathrm{P}$ (from $\mathrm{O}=\mathrm{P}(\mathrm{O}-$ choline $)(\mathrm{OH}) \mathrm{O}^{-}$or $\mathrm{O}=\mathrm{P}(\mathrm{O}$-choline $\left.) \mathrm{OH}_{2}\right)$, and the oxygen atoms from two molecules of water. The charge on $\mathrm{O}=\mathrm{P}(\mathrm{O}-$ choline $)(\mathrm{OH}) \mathrm{O}^{-}$was ignored because it is not part of the coordination sphere of the metal ion. After these considerations, the results were explained considering the molecular model of the PchP active site $[25,26,38]$ in addition to previously described data and theoretical calculations $[44,45,56-64]$ related to the coordination of the metal ion with water and their hydrolysis at different $\mathrm{pH}$ values, the interaction of carboxylic and carbonyl groups, the substitution of metal ions in the active site, and the hydrophobic cavity with a low $\varepsilon$ proximal to the active site of PchP. The inhibition produced by $\mathrm{Zn}^{2+}$ at $\mathrm{pH}$ 7.4 may be interpreted as the change from octahedral to tetrahedral coordination geometry, which is produced by the hydrolysis of the $\left[\mathrm{Zn}^{2+} \mathrm{L}_{2}^{-1} \mathrm{~L}_{2}^{0}\left(\mathrm{H}_{2} \mathrm{O}\right)_{2}\right]$ complex. $\mathrm{Zn}^{2+}$, which has an octahedral coordination at $\mathrm{pH} 5.0$ and forms a complex with a charge of zero $\left[\mathrm{Zn}^{2+} \mathrm{L}_{2}^{-1} \mathrm{~L}_{2}^{0}\left(\mathrm{H}_{2} \mathrm{O}\right)_{2}\right]$, may change to a negatively charged complex of either $\left[\mathrm{Zn}^{2+} \mathrm{L}_{2}^{-1} \mathrm{~L}_{2}^{0}(\mathrm{OH})^{-1}\left(\mathrm{H}_{2} \mathrm{O}\right)\right]^{-1}$ or $\left[\mathrm{Zn}^{2+} \mathrm{L}_{2}^{-1} \mathrm{~L}_{2}^{0}(\mathrm{OH})_{2}^{-1}\right]^{-2}$ at $\mathrm{pH}$ 7.4. Therefore, the loss of catalytic activity at $\mathrm{pH} 7.4$ may produce changes in the coordination geometry at the metal binding site of PchP from an octahedral (active enzyme) to a tetrahedral (inactive enzyme) arrangement. Contrary to what occurs with $\mathrm{Zn}^{2+}$, the neutral complex of $\left[\mathrm{Mg}^{2+} \mathrm{L}_{2}^{-1} \mathrm{~L}_{2}^{0}\left(\mathrm{H}_{2} \mathrm{O}\right)_{2}\right]$ that forms an octahedral complex does not change between $\mathrm{pH} 5.0$ and 7.4. The consequence is that at both $\mathrm{pH}$ values, the PchP activity is similar when $\mathrm{Mg}^{2+}$ is utilized as an activator ion [38] (Figure 2). An 
interesting point emergent of our results is to emphasize that the presence or absence of activity in enzymes of the HAD superfamily may be caused by the hydrolysis of the metal produced by variation of the $\mathrm{pH}$ in the reaction mixture. For example, an enzymatic activity measured at neutral or alkaline $\mathrm{pH}$ can be active when $\mathrm{Mg}^{2+}$ is present but can be inactivated by $\mathrm{Zn}^{2+}$ or other ions belonging to the transition metals. As above indicated, the another point of interest was to understand the catalytic mechanism of PchP with Pcho as the substrate, $\mathrm{Mg}^{2+}$ or $\mathrm{Zn}^{2+}$ as activators, and the effect produced by AACs. Saturation curves with different concentrations of Pcho analyzed in the DYNAFYT software have led to the conclusion that the catalytic mechanism follows a random sequential mechanism for the binding of Pcho, $\mathrm{Mg}^{2+}$, or $\mathrm{Zn}^{2+}$ (Figure 3) [15]. However, these ions do not change the $K_{\mathrm{M}}$ value of Pcho. The noteworthy difference between these ions is that the $K_{\mathrm{A}}$ value for $\mathrm{Zn}^{2+}$ is approximately one thousand times lower than the values obtained with $\mathrm{Mg}^{2+}$. Another difference is that $\mathrm{Zn}^{2+}$ is more effective than $\mathrm{Mg}^{2+}$ at avoiding the inhibition produced by high Pcho concentrations. A random mechanism also occurs for the interaction of a second substrate molecule at the second site of the enzyme, which apparently has an affinity for the choline moiety of the substrate or another AAC. These mechanisms are independent of the characteristics of the central metal ion; however, $\mathrm{Zn}^{2+}$ is more effective than $\mathrm{Mg}^{2+}$ at alleviating the inhibition produced by the entry of the second Pcho molecule or different AACs [15]. This result suggests that $\mathrm{Zn}^{2+}$ induces a conformational change in the active center that is communicated to the peripheral anionic site and produces a compact or closed structure. In contrast, a relaxed or open conformation occurs when $\mathrm{Mg}^{2+}$ acts as the metal ion activator of the enzyme. To confirm the presence of a second site for the alkylammonium moiety in the PchP molecule, the following compounds were utilized: trimethylamine, tetramethylammonium, choline, chlorocholine, betaine, hexamethonium, decamethonium, tubocurarine, and neostigmine. All these compounds produce inhibition with both competitive and partially uncompetitive components. The presence of two $K_{\mathrm{i}}$ values also indicates that these compounds, independent of the degree of inhibition produced (the changes produced for the nonalkylammonium moiety present in the inhibitor), might bind to two sites of PchP (e.g., for tetramethylammonium, the $K_{\mathrm{i}} 1$ and $K_{\mathrm{i}} 2$ values are 0.17 and $0.035 \mathrm{mM}$, respectively) [15]. The concordance between these results and the above-men-tioned bioinformatic studies led to the proposal that $\mathrm{PchP}$ contains an active site with subsites where the metal ion, the phosphate, and the trimethylammonium moieties are bound. The inhibitory site responsible for the inhibition by high substrate concentrations or different AACs could be a peripheral site located in the vicinity of the active site (Figures 1(b) and 1(c)).

\section{Biophysical Properties and Crystallization of PchP}

Simultaneously, attention was focused on studying the physicochemical properties of PchP to facilitate crystallizing the enzyme. The first approach to obtaining enough enzyme to achieve its crystallization and to study its physicochemical properties was performed as previously described [53]. The enzyme was purified from urea, and the inclusion bodies were solubilized and refolded by dialysis. The refolded PchP consisted of a mixture of native PchP and an alternatively folded enzyme aggregate that was slowly converted to the native state. It was proposed that the active enzyme is a dimer, and the catalytic parameters of native PchP for the hydrolysis of $p$-NPP were found to be in excellent agreement with the values reported previously for PchP expressed in Escherichia coli as an N-terminal fusion to intein or a histidine tag and purified in the folded state $[25,26,53]$. Although some data were collected, the preparation was not useful for obtaining crystals capable of diffracting. Therefore, efforts were focused on obtaining the enzyme as previously described [38]. Using this preparation technique, crystals were obtained [65], and the crystallization of PchP in the presence of different ligands will be used to solve its structure and to reveal the catalytic mechanism and the possible conformations produced by the different ligands. A structure of the enzyme has recently been obtained and is shown in Figure 4.

\section{Other Microorganisms Containing PchP}

Before the PA5292 gene in the P. aeruginosa PAO1 genome was found to be responsible for the synthesis of PchP [4], this protein was known as a hypothetical protein. This enzyme is also present in $P$. fluorescens, $P$. putida, and $P$. syringae $[49,66]$. The PchPs found in these bacteria were also activated by $\mathrm{Mg}^{2+}, \mathrm{Zn}^{2+}$, and $\mathrm{Cu}^{2+} ; \mathrm{Zn}^{2+}$ was the best metal activator of all these enzymes. The kinetic data and the $K_{\mathrm{A}}$ values for the metal ions defined two groups; one of the groups is formed by $P$. aeruginosa and $P$. putida and has a low affinity for $\mathrm{Mg}^{2+}$ with apparent $K_{\mathrm{A}}$ values of $130 \mu \mathrm{M}$ and $190 \mu \mathrm{M}$, respectively, and the other group is formed by $P$. fluorescens and $P$. syringae, which have a high affinity for $\mathrm{Mg}^{2+}$ with apparent $K_{\mathrm{A}}$ values of $38 \mu \mathrm{M}$ and $30 \mu \mathrm{M}$, respectively. Catalytic efficiency is defined as the relationship $V_{\max } / K_{\mathrm{M}}$; in this respect, the enzyme isolated from $P$. fluorescens is better at catalyzing the hydrolysis of $p$-NPP in the presence of $\mathrm{Mg}^{2+}, \mathrm{Zn}^{2+}$, or $\mathrm{Cu}^{2+}$ with $V_{\max } / K_{\mathrm{M}}$ values of $2.3,2.5$, and 3.4 for $\mathrm{Mg}^{2+}, \mathrm{Zn}^{2+}$, and $\mathrm{Cu}^{2+}$, respectively, followed by those of $P$. aeruginosa and $P$. putida ( $\cong 0.3-0.4 \mathrm{Umg}^{-1} \mathrm{mM}^{-1}$ for the three metals) and finally by $P$. syringae $\left(\cong 0.03-0.04 \mathrm{Umg}^{-1} \mathrm{mM}^{-1}\right.$, for the three metals) [49]. Finally, information from many genomes utilizing the precomputed BLAST results for "http://www.ncbi.nlm.nih.gov/protein/15600485 phosphorylcholine phosphatase [Pseudomonas aeruginosa PAO1]" matched 351 proteins in 173 species (331 bacteria, represented principally by Pseudomonas and Burkholderia species such as $P$. aeruginosa, $P$. fluorescens, $P$. syringae, $P$. savastanoi, P. entomophila, P. putida, B. ambifaria, B. cenocepacia, B. multivorans, and other bacteria such as Azospirillum sp, and Lutiella nitrofe). PchP activity has also been found in plant pathogenic fungi such as Glomerella graminicola, Leptosphaeria maculans, Pyrenophora teres, P. tritici, Gibberella 
zeae, Nectria haematococca, Verticillium albo-atrum, Magnaporthe oryzae, and Phaeosphaeria nodorum [67]. A multiple alignment of PchP found in different organisms utilizing Clustal X [19] is shown in Figure 5(a); evolutionary relationships and a phylogenetic tree produced by the software [2023] are shown in Figure 5(b). Because all of these organisms might contain PchP with similar properties to the enzyme found in $P$. aeruginosa, and the crystallized enzyme in the presence of different ligands will soon be solved, the global approach used by our group to study PchP will culminate with the determination of its structure. We expect that further studies might be applied to the development of new and very effective inhibitors of PchP through metal binding, phosphate binding, or alkylammonium binding levels.

\section{Acknowledgments}

Carlos Eduardo Domenech is an honorary professor consult at the UNRC (ad honorem) and is a retired career member of the Consejo Nacional de Investigaciones Científicas y Técnicas (CONICET). Angela Teresita Lisa is career member of the CONICET. Paola Rita Beassoni acknowledges fellowship support from CONICET; Lisandro Horacio Otero is from CONICET and the Ministerio de Ciencia y TécnologíaCórdoba (MinCyT-Cba). The authors thank Dr. Armando Albert and Dr. Lourdes Infantes (Instituto de QuímicaFísica "Rocasolano", Consejo Superior de Investigaciones Científicas, Ciencia e Investigación, Madrid, Spain) who allowed them to use the structure of PchP before publication (Otero et al. 2011, in preparation). They would also like to thank Dr. Danilo Gonzalez-Nilo of the Centro de Bioinformática y Simulación Molecular, Universidad de Talca, Talca, Chile, for his valuable help on the docking experiments performed with the ICM program. They also appreciate the participation of Cristhian Boetsch and Diego G. Sanchez (UNRC) in the performance of bioinformatics and molecular experiments, respectively. Their thanks are to ACD, Inc. (http://www.acdlabs.com), which provided the ionization con-stants for phosphorylcholine. This work was supported by grants from SECYT-UNRC, and CONICET of Argentina given to Angela Teresita Lisa, and MinCyT-Cba given to Angela Teresita Lisa and Paola Rita Beassoni. Angela Teresita Lisa also acknowledges the support from Red Bio-Bio-Mol I and Red de Bioinformática y Biología de Sistemas from the Secretaría de Políticas Universitarias (SPU) of Argentina. Lisandro Horacio Otero would also like to thank Fundación Carolina, Spain for fellowship support.

\section{Disclosure}

Carlos Eduardo Domenech dedicates this paper to Professor Dr. Antonio Blanco, National University of Cordoba, Argentina, from whom Carlos Eduardo Domenech learned that the quality of a scientist is measured by the honesty, the seriousness, and responsibility in scientific work, selfless teaching, and mutual respect between all laboratory personnel and the entire scientific community.

\section{References}

[1] A. T. Lisa, P. R. Beassoni, M. J. Massimelli, L. H. Otero, and C. E. Domenech, "A glance on Pseudomonas aeruginosa phosphorylcholine phosphatase, an enzyme whose synthesis depends on the presence of choline in its environment," in Communicating Current Research and Educational Topics and Trends in Applied Microbiology, pp. 255-262, Formatex, Badajoz, Spain, 2007.

[2] M. N. Garrido, T. A. Lisa, S. T. Albelo, G. I. Lucchesi, and C. E. Domenech, "Identification of the Pseudomonas aeruginosa acid phosphatase as a phosphorylcholine phosphatase activity," Molecular and Cellular Biochemistry, vol. 94, no. 1, pp. 89-95, 1990.

[3] M. A. Salvano and C. E. Domenech, "Kinetic properties of purified Pseudomonas aeruginosa phosphorylcholine phosphatase indicated that this enzyme may be utilized by the bacteria to colonize in different environments," Current Microbiology, vol. 39, no. 1, pp. 1-8, 1999.

[4] M. J. Massimelli, P. R. Beassoni, M. A. Forrellad et al., "Identification, cloning, and expression of Pseudomonas aeruginosa phosphorylcholine phosphatase gene," Current Microbiology, vol. 50, no. 5, pp. 251-256, 2005.

[5] M. J. Wargo, T. C. Ho, M. J. Gross, L. A. Whittaker, and D. A. Hogan, "GbdR regulates Pseudomonas aeruginosa $\mathrm{plcH}$ and pchP transcription in response to choline catabolites," Infection and Immunity, vol. 77, no. 3, pp. 1103-1111, 2009.

[6] M. J. Wargo, B. S. Szwergold, and D. A. Hogan, "Identification of two gene clusters and a transcriptional regulator required for Pseudomonas aeruginosa glycine betaine catabolism," Journal of Bacteriology, vol. 190, no. 8, pp. 2690-2699, 2008.

[7] M. J. Massimelli, D. G. Sanchez, M. V. Buchieri et al., "Choline catabolism, $\delta^{54}$ factor and $\mathrm{NtrC}$ are required for the full expression of the Pseudomonas aeruginosa phosphorylcholine phosphatase gene," Microbiological Research, vol. 166, no. 5, pp. 380-390, 2010.

[8] A. T. Lisa, M. N. Garrido, and C. E. Domenech, "Induction of acid phosphatase and cholinesterase activities in Pseudomonas aeruginosa and their in-vitro control by choline, acetylcholine and betaine," Molecular and Cellular Biochemistry, vol. 50, no. 2, pp. 149-155, 1983.

[9] A. T. Lisa, M. N. Garrido, and C. E. Domenech, "Pseudomonas aeruginosa acid phosphatase and cholinesterase induced by choline and its metabolic derivatives may contain a similar anionic peripheral site," Molecular and Cellular Biochemistry, vol. 63, no. 2, pp. 113-118, 1984.

[10] G. I. Lucchesi, A. T. Lisa, C. H. Casale, and C. E. Domenech, "Carnitine resembles choline in the induction of cholinesterase, acid phosphatase, and phospholipase $\mathrm{C}$ and in its action as an osmoprotectant in Pseudomonas aeruginosa," Current Microbiology, vol. 30, no. 1, pp. 55-60, 1995.

[11] T. Nishijyo, D. Haas, and Y. Itoh, "The CbrA-CbrB twocomponent regulatory system controls the utilization of multiple carbon and nitrogen sources in Pseudomonas aeruginosa," Molecular Microbiology, vol. 40, no. 4, pp. 917-931, 2001.

[12] W. Li and C. D. Lu, "Regulation of carbon and nitrogen utilization by CbrAB and NtrBC two-component systems in Pseudomonas aeruginosa," Journal of Bacteriology, vol. 189, no. 15, pp. 5413-5420, 2007.

[13] X. X. Zhang and P. B. Rainey, "Dual involvement of CbrAB and NtrBC in the regulation of histidine utilization in Pseudomonas fluorescens SBW25," Genetics, vol. 178, no. 1, pp. 185195, 2008. 
[14] J. Kyte and R. F. Doolittle, "A simple method for displaying the hydropathic character of a protein," Journal of Molecular Biology, vol. 157, no. 1, pp. 105-132, 1982.

[15] L. H. Otero, P. R. Beassoni, C. Boetsch, A. T. Lisa, and C. E. Domenech, "Different effects of $\mathrm{Mg}^{2+}$ and $\mathrm{Zn}^{2+}$ on the two sites for alkylammonium compounds in Pseudomonas aeruginosa phosphorylcholine phosphatase," Enzyme Research, vol. 2011, Article ID 918283, 7 pages, 2011.

[16] M. J. Massimelli, Localización y caracterización de secuencias promotoras y reguladoras del gen que codifica para la actividad fosforilcolina fosfatasa de Pseudomonas aeruginosa, Doctoral Thesis, Universidad Nacional de Río Cuarto, Córdoba, Argentina, 2008.

[17] Y. Itoh, T. Nishijyo, and Y. Nakada, "Histidine catabolism and catabolite regulation," in Pseudomonas, J. L. Ramos and A. Filloux, Eds., pp. 371-395, Springer, Dordrecht, The Netherlands, 2007.

[18] A. B. Hervas, I. Canosa, and E. Santero, "Transcriptome analysis of Pseudomonas putida in response to nitrogen avail-ability," Journal of Bacteriology, vol. 191, no. 1, pp. 416-420, 2008.

[19] M. A. Larkin, G. Blackshields, N. P. Brown et al., "Clustal W and Clustal X version 2.0," Bioinformatics, vol. 23, no. 21, pp. 2947-2948, 2007.

[20] N. Saitou and M. Nei, “The neighbor-joining method: a new method for reconstructing phylogenetic trees," Molecular Biology and Evolution, vol. 4, no. 4, pp. 406-425, 1987.

[21] N. Takezaki, A. Rzhetsky, and M. Nei, "Phylogenetic test of the molecular clock and linearized trees," Molecular Biology and Evolution, vol. 12, no. 5, pp. 823-833, 2004.

[22] E. Zuckerkandl and L. Pauling, "Evolutionary divergence and convergence in proteins," in Evolving Genes and Proteins, pp. 97-166, 1965.

[23] K. Tamura, J. Dudley, M. Nei, and S. Kumar, "MEGA4: molecular evolutionary genetics analysis (MEGA) software version 4.0," Molecular Biology and Evolution, vol. 24, no. 8, pp. 15961599, 2007.

[24] A. Marchler-Bauer, S. Lu, J. B. Anderson et al., "CDD: a conserved domain database for the functional annotation of proteins," Nucleic Acids Research, vol. 39, pp. D225-D229, 2011.

[25] P. R. Beassoni, L. H. Otero, M. J. Massimelli, A. T. Lisa, and C. E. Domenech, "Critical active-site residues identified by site-directed mutagenesis in Pseudomonas aeruginosa phosphorylcholine phosphatase, a new member of the haloacid dehalogenases hydrolase superfamily," Current Microbiology, vol. 53, no. 6, pp. 534-539, 2006.

[26] P. R. Beassoni, L. H. Otero, A. T. Lisa, and C. E. Domenech, "Using a molecular model and kinetic experiments in the presence of divalent cations to study the active site and catalysis of Pseudomonas aeruginosa phosphorylcholine phosphatase," Biochimica et Biophysica Acta: Proteins and Proteomics, vol. 1784, no. 12, pp. 2038-2044, 2008.

[27] E. V. Koonin and R. L. Tatusove, "Computer analysis of bacterial haloacid dehalogenases defines a large superfamily of hydrolases with diverse specificity, application of an iterative approach to database search," Journal of Molecular Biology, vol. 244, no. 1, pp. 125-132, 1994.

[28] W. Wang, R. Kim, J. Jancarik, H. Yokota, and S. H. Kim, "Crystal structure of phosphoserine phosphatase from Methanococcus jannaschii, a hyperthermophile, at $1.8 \AA$ resolution," Structure, vol. 9, no. 1, pp. 65-71, 2001.

[29] L. A. Kelley and M. J. E. Sternberg, "Protein structure prediction on the Web: a case study using the Phyre server," Nature Protocols, vol. 4, no. 3, pp. 363-371, 2009.
[30] M. N. Garrido, A. T. Lisa, and C. E. Domenech, "Pseudomonas aeruginosa acid phosphatase contains an anionic site with a trimethyl subsite: kinetic evidences obtained with alkylammonium ions," Molecular and Cellular Biochemistry, vol. 84, no. 1, pp. 41-49, 1988.

[31] A. E. Lucchini, A. T. Lisa, and C. E. Domenech, "Choline derivatives increase two different acid phosphatases in Rhizobium meliloti and Pseudomonas aeruginosa," Archives of Microbiology, vol. 153, no. 6, pp. 596-599, 1990.

[32] J. C. M. Hafkenscheid, "Properties of an acid phosphatase in Escherichia coli," Biochemica et Biophysica Acta, vol. 167, no. 3, pp. 582-589, 1968.

[33] A. A. A. Magboul and P. L. H. McSweeney, "Purification and properties of an acid phosphatase from Lactobacillus curvatus DPC2024," International Dairy Journal, vol. 9, no. 12, pp. 849855, 2000.

[34] S. Deng, J. G. Elkins, L. H. Da, L. M. Botero, and T. R. McDermott, "Cloning and characterization of a second acid phosphatase from Sinorhizobium meliloti strain 104A14," Archives of Microbiology, vol. 176, no. 4, pp. 255-263, 2001.

[35] R. L. Felts, T. J. Reilly, and J. J. Tanner, "Structure of Francisella tularensis AcpA: prototype of a unique superfamily of acid phosphatases and phospholipases C," Journal of Biological Chemistry, vol. 281, no. 40, pp. 30289-30298, 2006.

[36] C. Passariello, C. Forleo, V. Micheli et al., "Biochemical characterization of the class B acid phosphatase (AphA) of Escherichia coli MG1655," Biochimica et Biophysica Acta, vol. 1764, no. 1, pp. 13-19, 2006.

[37] J. B. Stock, B. Rauch, and S. Roseman, "Periplasmic space in Salmonella typhimurium and Escherichia coli," Journal of Biological Chemistry, vol. 252, no. 21, pp. 7850-7861, 1997.

[38] L. H. Otero, P. R. Beassoni, A. T. Lisa, and C. E. Domenech, "Transition from octahedral to tetrahedral geometry causes the activation or inhibition by $\mathrm{Zn}^{2+}$ of Pseudomonas aeruginosa phosphorylcholine phosphatase," BioMetals, vol. 23, no. 2, pp. 307-314, 2010.

[39] S. J. Roberts, A. J. Stewart, P. J. Sadler, and C. Farquharson, "Human PHOSPHO1 exhibits high specific phosphoethanolamine and phosphocholine phosphatase activities," Biochemical Journal, vol. 382, no. 1, pp. 59-65, 2004.

[40] S. J. Roberts, A. J. Stewart, R. Schmid et al., "Probing the substrate specificities of human PHOSPHO1 and PHOSPHO2," Biochimica et Biophysica Acta, vol. 1752, no. 1, pp. 73-78, 2005.

[41] J. L. García, A. R. Sanchez-Beato, F. J. Medrano, and E. Lopez, "Versatility of choline binding domain," Microbial Drug Resistance, vol. 4, no. 1, pp. 25-36, 1998.

[42] P. R. Beassoni, L. H. Otero, C. Boetsch, C. E. Domenech, F. D. González-Nilo, and A. T. Lisa, "Site-directed mutations and kinetic studies show key residues involved in alkylammonium interactions and reveal two sites for phosphorylcholine in Pseudomonas aeruginosa phosphorylcholine phosphatase," Biochimica et Biophysica Acta, vol. 1814, no. 7, pp. 858-863, 2011.

[43] C. E. Domenech, T. A. Lisa, M. A. Salvano, and M. N. Garrido, "Pseudomonas aeruginosa acid phosphatase activation by divalent cations and inhibition by aluminium ion," FEBS Letters, vol. 299, no. 1, pp. 96-98, 1992.

[44] M. M. Harding, "The geometry of metal-ligand interactions relevant to proteins. II. angles at the metal atom, additional weak metal-donor interactions," Acta Crystallographica Section $D$, vol. 56, no. 7, pp. 857-867, 2000.

[45] M. M. Harding, "Geometry of metal-ligand interactions in proteins," Acta Crystallographica Section D, vol. 57, no. 3, pp. 401-411, 2001. 
[46] M. M. Harding, "The architecture of metal coordination groups in proteins," Acta Crystallographica Section D, vol. 60, no. 5, pp. 849-859, 2004.

[47] M. M. Harding, "Small revisions to predicted distances around metal sites in proteins," Acta Crystallographica Section D, vol. 62, no. 6, pp. 678-682, 2006.

[48] M. Lippi, A. Passerini, M. Punta, B. Rost, and P. Frasconi, "MetalDetector: a web server for predicting metal-binding sites and disulfide bridges in proteins from sequence," Bioinformatics, vol. 24, no. 18, pp. 2094-2095, 2008.

[49] L. H. Otero, Residuos aminoacídicos de la fosforilcolina fosfatasa de Pseudomonas aeruginosa involucrados en la interacción con iones metálicos y con compuestos de alquilamonio, Doctoral Thesis, Universidad Nacional de Río Cuarto, Córdoba, Argentina, 2010.

[50] R. G. Pearson, "Hard and soft acids and bases," Journal of the American Chemical Society, vol. 85, no. 22, pp. 3533-3539, 1963.

[51] R. G. Pearson, "Acids and bases," Science, vol. 151, no. 3707, pp. 172-177, 1966.

[52] R. G. Parr and R. G. Pearson, "Absolute hardness: companion parameter to absolute electronegativity," Journal of the American Chemical Society, vol. 105, no. 26, pp. 7512-7516, 1983.

[53] P. R. Beassoni, F. P. de Berti, L. H. Otero et al., "A biophysical characterization of recombinant Pseudomonas aeruginosa phos-phorylcholine phosphatase: evidences of two folding pathways," Protein Expression and Purification, vol. 71, pp. 153-159, 2010.

[54] T. Dudev and C. Lim, "Metal binding in proteins: the effect of the dielectric medium," Journal of Physical Chemistry B, vol. 104, no. 15, pp. 3692-3694, 2000.

[55] P. Kuzmic, "Program DYNAFIT for the analysis of enzyme kinetic data: application to HIV proteinase," Analytical Biochemistry, vol. 237, no. 2, pp. 260-273, 1996.

[56] A. K. Katz, J. P. Glusker, G. D. Markham, and C. W. Bock, "Deprotonation of water in the presence of carboxylate and magnesium ions," The Journal of Physical Chemistry B, vol. 102, no. 33, pp. 6342-6350, 1998.

[57] M. Pavlov, P. E. M. Siegbahn, and M. Sandström, "Hydration of beryllium, magnesium, calcium, and zinc ions using density functional theory," The Journal of Physical Chemistry A, vol. 102, no. 1, pp. 219-228, 1998.

[58] F. C. Lightstone, E. Schwegler, R. Q. Hood, F. Gygi, and G. Galli, "A first principles molecular dynamics simulation of the hydrated magnesium ion," Chemical Physics Letters, vol. 343, no. 5-6, pp. 549-555, 2001.

[59] L. Bochatay and P. Persson, "Metal ion coordination at the water-manganite (-MnOOH) interface: II. An EXAFS study of zinc(II)," Journal of Colloid and Interface Science, vol. 229, no. 2, pp. 593-599, 2000.

[60] T. Dudev and C. Lim, "Metal selectivity in metalloproteins: $\mathrm{Zn}^{2+}$ vs $\mathrm{Mg}^{2+}$," Journal of Physical Chemistry B, vol. 105, no. 19, pp. 4446-4452, 2001.

[61] T. Dudev and C. Lim, "Principles governing Mg, Ca, and Zn binding and selectivity in proteins," Chemical Reviews, vol. 103, no. 3, pp. 773-787, 2003.

[62] X. Li, G. Pan, Y. Qin, T. Hu, Z. Wu, and Y. Xie, "EXAFS studies on adsorption-desorption reversibility at manganese oxideswater interfaces: II. Reversible adsorption of zinc on $\delta$-MnO2," Journal of Colloid and Interface Science, vol. 271, no. 1, pp. 3540, 2004.

[63] M. Zhu and G. Pan, "Quantum chemical studies of mononuclear zinc species of hydration and hydrolysis," The Journal of Physical Chemistry, vol. 109, no. 33, pp. 7648-7652, 2005.
[64] S. Kluge and J. Weston, "Can a hydroxide ligand trigger a change in the coordination number of magnesium ions in biological systems?" Biochemistry, vol. 44, no. 12, pp. 4877-4885, 2005.

[65] L. H. Otero, P. R. Beassoni, C. E. Domenech, A. T. Lisa, and A. Albert, "Crystallization and preliminary X-ray diffraction analysis of Pseudomonas aeruginosa phosphorylcholine phosphatase," Acta Crystallographica Section F, vol. 66, no. 8, pp. 957-960, 2010.

[66] P. R. Beassoni, Relación entre estructura y función de la fosforilcolina fosfatasa de Pseudomonas aeruginosa y otras bacterias del género Pseudomonas, Doctoral Thesis, Universidad Nacional de Río Cuarto, Córdoba, Argentina, 2006.

[67] G. L. Winsor, T. van Rossum, R. Lo et al., "Pseudomonas genome database: facilitating user-friendly, comprehensive comparisons of microbial genomes," Nucleic Acids Research, vol. 37, no. 1, pp. D483-D488, 2009. 

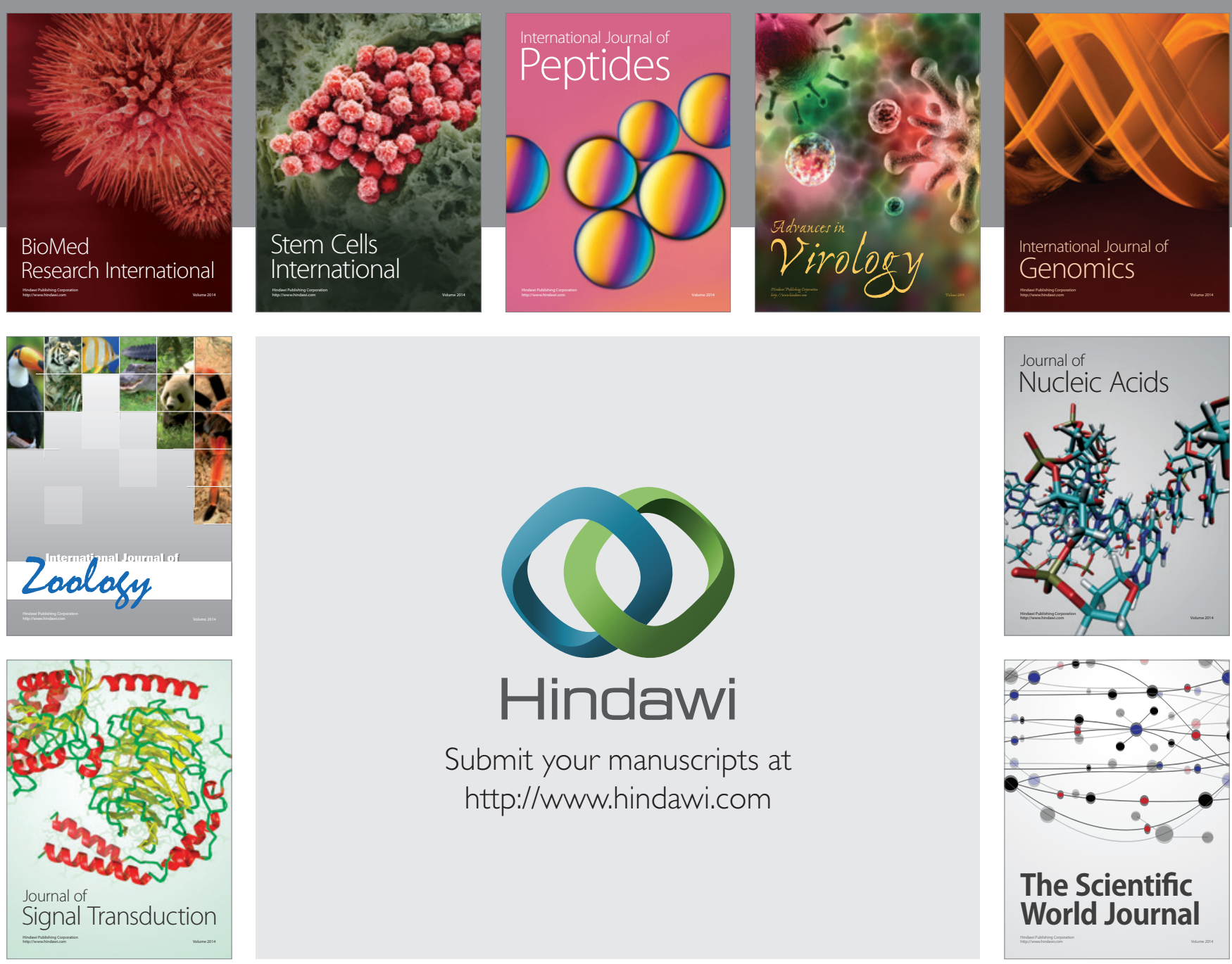

Submit your manuscripts at

http://www.hindawi.com
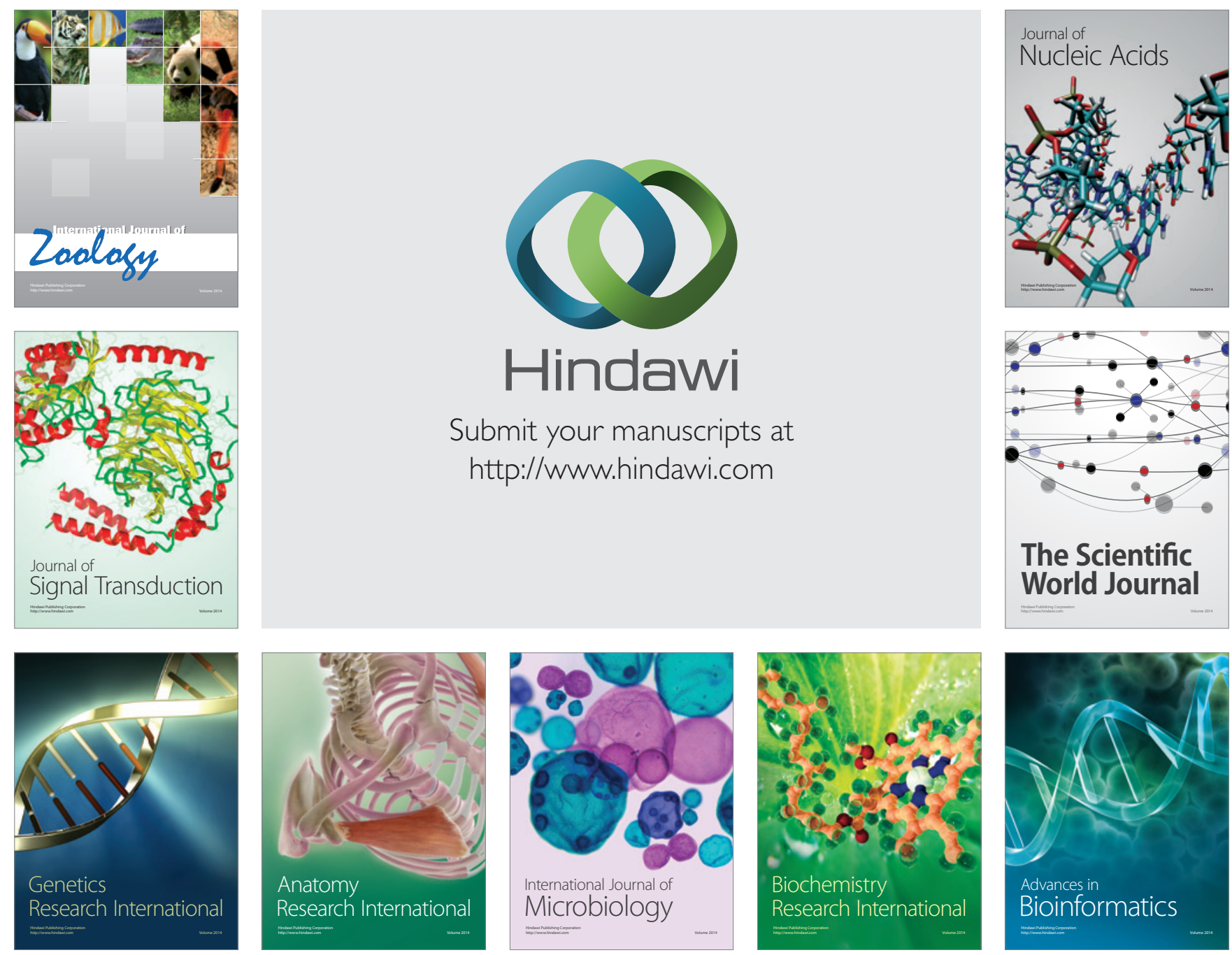

The Scientific World Journal
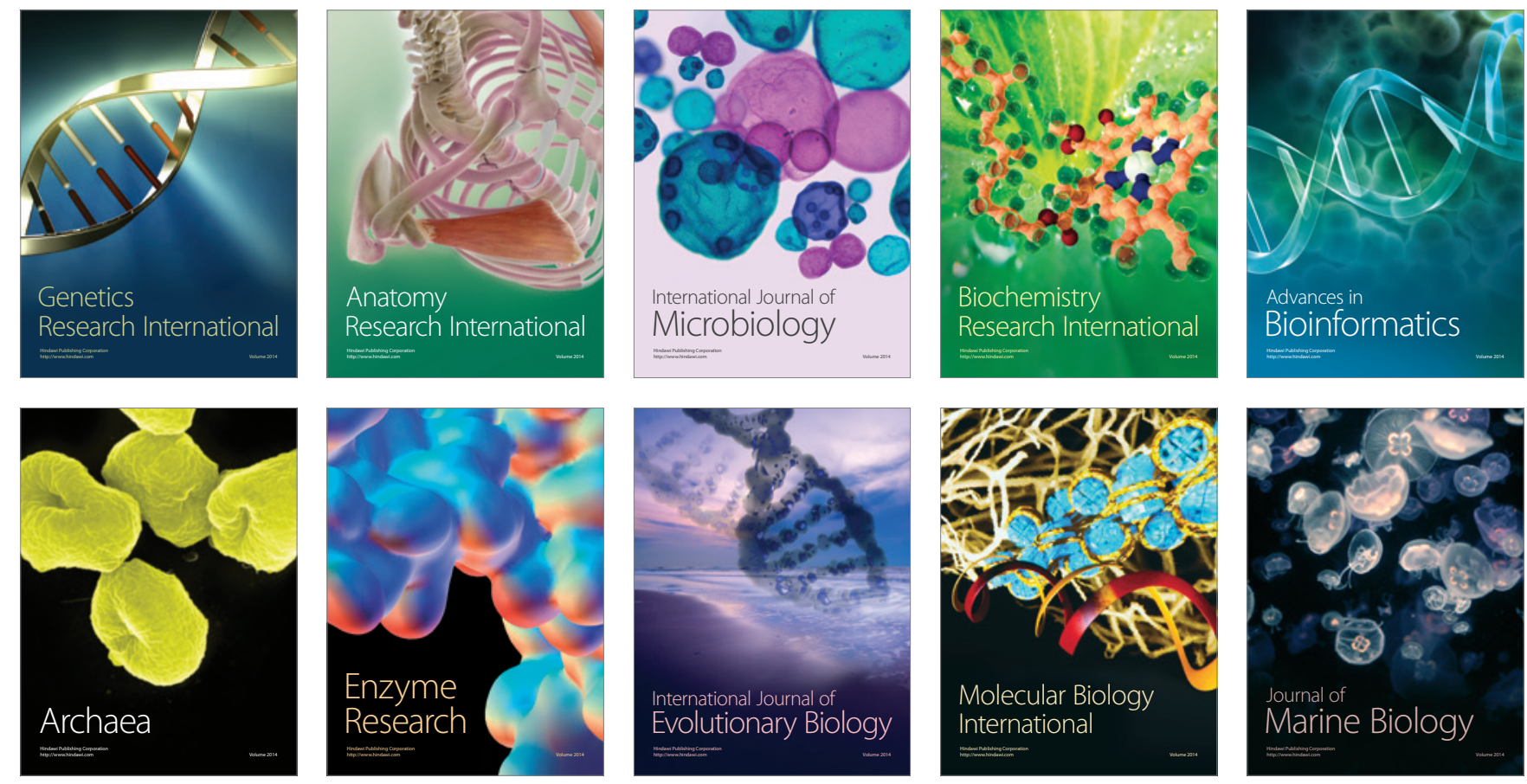